Caring is Costly: People Avoid the Cognitive Work of Compassion

Julian A. Scheffer ${ }^{1}$, C. Daryl Cameron ${ }^{1,2}, \&$ Michael Inzlicht ${ }^{3,4}$

${ }^{1}$ Department of Psychology, The Pennsylvania State University, University Park, PA, USA

${ }^{2}$ Rock Ethics Institute, The Pennsylvania State University, University Park, PA, USA

${ }^{3}$ Department of Psychology, University of Toronto, Scarborough, ON, CAN

${ }^{4}$ Rotman School of Management, University of Toronto, Toronto, ON, CAN

Address correspondence to the first author jas1314@psu.edu

Author Note

This article is accepted at the Journal of Experimental Psychology: General.

(C) 2021, American Psychological Association. This paper is not the copy of record and may not exactly replicate the final, authoritative version of the article. Please do not copy or cite without authors' permission. The final article will be available, upon publication, via its DOI: $10.1037 / x g e 0001073$

Data and syntax can be accessed at the Open Science Framework: https://osf.io/k25yr/. 


\begin{abstract}
Compassion - the warm, caregiving emotion that emerges from witnessing the suffering of others - has long been considered an important moral emotion for motivating and sustaining prosocial behavior. Some suggest that compassion draws from empathic feelings to motivate prosocial behavior, while others try to disentangle these processes to examine their different functions for human pro-sociality. Many suggest that empathy, which involves sharing in others' experiences, can be biased and exhausting, whereas warm compassionate concern is more rewarding and sustainable. If compassion is indeed a warm and positive experience, then people should be motivated to seek it out when given the opportunity. Here, we ask whether people spontaneously choose to feel compassion, and whether such choices are associated with perceiving compassion as cognitively costly. Across all studies, we found that people opted to avoid compassion when given the opportunity; reported compassion to be more cognitively taxing than empathy and objective detachment; and opted to feel compassion less often to the degree they viewed compassion as cognitively costly. We also revealed two important boundary conditions: first, people were less likely to avoid compassion for close (vs. distant) others, and this choice difference was associated with viewing compassion for close others as less cognitively costly. Second, in the final study we found that with more contextually enriched and immersive pleas for help, participants preferred to escape feeling compassion, though their preference did not differ from also escaping remaining objectively detached. These results temper strong arguments that compassion is an easier route to prosocial motivation.
\end{abstract}

Keywords: compassion; empathy; effort; motivation; emotion regulation 


\section{Caring is costly: People avoid the cognitive work of compassion}

When faced with the suffering of others — such as the plea of a homeless person-people are equipped with a variety of moral responses. Across the sciences and humanities, two of the most well-studied are empathy and compassion. There is some debate on the differences between empathy and compassion, with many suggesting that empathy entails vicarious resonance with others' experiences, whereas compassion entails a caring concern and motivation to help (Singer \& Klimecki, 2014). Furthermore, many scholars have proposed that empathy and compassion are worth cultivating, with studies revealing links to prosocial behaviors (for reviews, see Batson, 2011; Decety et al., 2016; Goetz et al., 2010). However, an important discussion has emerged about whether and how empathy and compassion may have different psychological characteristics, with possible implications for sustaining prosocial motivations.

\section{Conceptualizing Compassion and Empathy}

Compassion and empathy have been conceptualized in different ways across psychology and neuroscience, with part of the discrepancies reflecting different usages of the terms involved (see Batson, 2011; Goetz et al., 2010). Some scholars (e.g., Batson, 2009; Decety \& Cowell, 2014; Hall \& Schwartz, 2019) have discussed the many processes that can be captured by the term "empathy". Though generally considered to have multiple facets, "empathy" is often described by its component parts such as experience sharing - that is, sharing in the experiences and feelings of another person - or cognitive perspective-taking - putting oneself into the mind of another person and imagining what they are thinking or feeling (Decety \& Cowell, 2014; Zaki \& Ochsner, 2012). At times, empathy may be constrained to just experience sharing, which is often contrasted with compassion in debates over their respective prosocial implications (Bloom, 2017; Jordan et al., 2016; Klimecki \& Singer, 2014; Prinz, 2011). For example, in discussions of 
the costs of caregiving within close relationships and in more professional (e.g., medical) settings, the risks of burnout from emotionally matching the suffering of others through empathy is contrasted against having more caring emotional stances through compassion (Bloom, 2017; Figley, 2002; Klimecki \& Singer, 2012).

On one hand, some conceptualize compassion as a separate but related emotional experience from empathy (e.g., DeSteno, 2015), with one review defining it explicitly as "the feeling that arises in witnessing another's suffering and that motivates a subsequent desire to help" (Goetz et al., 2010, p. 531). Compassion has been further defined as:

Not a sharing of another person's emotional state, which will vary depending on what the other person's emotional experience seems to be, but an emotion of its own...In compassion, the emotion is felt and shaped in the person feeling it not by whatever the other person is believed to be feeling, but by feeling personal distress at the suffering of another and wanting to ameliorate it" (Lazarus, 1991, p. 289, as cited in Goetz et al., 2010).

On the other hand, some conceptualize compassion as a motivational sub-component of the broader empathy construct (see Decety \& Cowell, 2014). For instance, contemplative traditions view empathic resonance as a core feature of fully developed compassion, with compassion including emotion, motivation, and behavior (Roeser et al., 2018). Furthermore, Strauss and colleagues (2016) reviewed conceptualizations of compassion and proposed that compassion includes recognition of suffering and its universality, emotional resonance/empathy, tolerating personal distress, and a motivation to relieve suffering.

Similarly, Batson's (2011) model of empathic concern and altruistic motivation proposes notable overlap between compassion and empathy. This model defines empathic concern as 
"other-oriented emotions elicited by and congruent with the perceived welfare of someone else" (Batson, 2011, p. 11). According to this definition, empathic concern involves congruence with the affective valence of another's experience, which resembles experience sharing. Batson (2011) further suggests that empathic concern has the capacity to produce altruistic motivation, including a range of feelings that resemble compassion. Even as compassion and empathy may be separated in some cases, they may often overlap in many others (Batson, 2011; Decety \& Cowell, 2014; Depow et al., 2021; Goetz et al., 2010; Kanske et al., 2015). Recently, researchers have also used ecological momentary assessment (EMA) methods to examine how people experience empathy in naturalistic settings, with people reporting experience sharing and compassion (as well as perspective-taking) co-occurring in roughly $75 \%$ of their experiences (Depow et al., 2021). Nevertheless, the scientific and ethical debates over empathy and compassion suggest important distinctions between them to consider, and the current project was motivated to empirically examine this contrast.

Some work has attempted to distinguish compassion and empathy based on their consequences for the person experiencing them. Empathy facilitates understanding what other people are feeling (Batson \& Ahmad, 2009; Bruneau et al., 2015; Schumann et al., 2014), but is thought to pose risks for vicarious distress and burnout that may impede prosocial motivation (Bloom, 2017; Prinz, 2011). By contrast, compassion generates warm and affiliative responseslike a parent tending to a crying child (Singer \& Klimecki, 2014) — with less immediate costs to the caregiver and instead, more positive affective states (Stellar \& Keltner, 2014) that may sustain prosocial motivation. Additionally, some research in neuroscience has found that compassion may be more pleasant than empathy: when focused on suffering strangers, people described empathy as aversive whereas compassion was described as pleasant, and these reports 
were associated with neural activity associated with distress for empathy (e.g., insula) and reward for compassion (e.g., ventral striatum; Klimecki et al., 2014). Other related work found that compassion-meditation when viewing others' suffering promoted more positive affect states (Engen \& Singer, 2015). However, other work found that although compassion was forecasted as positive, it was actually experienced by participants as a negative state (Condon \& Barrett, 2013).

More recent work using factor analysis has found that self-reported trait empathy and compassion loaded onto separate factors (Jordan et al., 2016; Mayukha et al., 2020) that differentially associated with prosocial behavior (Jordan et al., 2016) and empathic accuracy (Mayukha et al., 2020), but this work did not test the relative costs of each. Moreover, some work has found that trait compassion may also associate with empathic performance tasks (e.g., Dziobak et al., 2008). Though compassion is thought by some to be less challenging to cultivate than empathy (Bloom, 2017), these supposedly distinct experiences have similar deficits (e.g., in response to mass suffering, Cameron \& Payne, 2011; in response to outgroups, Cikara et al., 2011). Moreover, some work suggests that to cultivate compassion, people might need to exert effortful control to avoid being overwhelmed with personal distress (Eisenberg et al., 1996, 1998; Eisenberg \& Eggum, 2009; Gilbert, 2018; Goetz et al., 2010). Therefore, a key feature of these findings is that if people fail to exert this effortful control, then distress may ultimately outweigh any compassionate feelings and motivation to care for others. Finally, many contemplative traditions suggest that intentional practice may be needed to sustain compassion for a broad array of targets (Roeser et al., 2018), implying that compassionate feelings may require considerable effort. 
Summary. There are some perspectives that treat compassion and empathy as distinct psychological experiences and others that treat compassion as merely a motivational facet of empathy. Regardless of these definitional debates, compassion and empathy are often considered to have different consequences for effective care, with empathy usually positioned as disadvantageous because of liabilities for burnout and compassion promoted as a positive alternative. Yet not all positions agree on whether compassion is easy or challenging to cultivate. Here, we directly examine the role of ease and effort in choosing to generate compassion.

\section{The Law of Less Work and Moral Emotions}

Decades of research documented peoples' strong preferences to avoid mental and physical effort: the law of less work suggests that humans and non-human animals prefer less effortful courses of actions (Fiske \& Taylor, 1984; Hosking et al., 2014, 2015a, 2015b; Hull, 1943; though see Inzlicht et al., 2018). In order to study mental effort avoidance in humans, cognitive neuroscience studies have adopted free choice approaches. For instance, Kool and colleagues (2010) provided people with two decks to choose from-one that provided participants with more instances of task switching (thought to involve mental effort), and the other with less instances of task switching. Participants were found to avoid the deck with a higher proportion of task switching, and their preferences associated with perceiving this deck as more mentally demanding (Kool et al., 2010). In related work, Westbrook and colleagues (2013) similarly adopted free choices approaches and found that people were willing to forgo higher payouts in order to avoid completing more mentally demanding tasks.

Affective scientists can adopt these free choice approaches (e.g., Lockwood et al., 2017; Miralles et al., 2019) to assess motivation to feel moral emotions rather than rely on self-reports. This methodological advance is important given people may fear the social and reputational 
consequences of not appearing compassionate (Batson, 2011). As an example of adopting free choice approaches to examine motivation to generate moral responses, prior work examined whether people would choose to feel empathy for strangers (Cameron et al., 2019). Participants completed trials of the empathy selection task in which they chose between either feeling empathy or remaining objectively detached from strangers, modeling the response options from prior empathy regulation research (Shaw et al., 1994). The free choice approach allowed participants to use situation-selection, an antecedent form of emotion-regulation (Gross, 2001). In this work, participants preferred to avoid empathy when given the choice, and their preferences associated with post-task ratings of felt cognitive effort. Furthermore, their choices for empathy were impacted by experimental manipulations of empathic efficacy (Cameron et al., 2019), showing that effort costs accounted for motivation to avoid empathy. This method has also been extended to examine empathy regulation in physicians (Cameron \& Inzlicht, 2020), motivational incentives for empathy regulation (e.g., financial and social-relational; Ferguson et al., 2020), and whether loneliness associates with empathy regulation (Hu et al., 2020). Therefore, the free choice approach may afford a new avenue for isolating compassion from empathy, examining whether motivations to regulate one over the other may differ in meaningful ways, and determine why this might be the case (e.g., differing effort costs).

\section{Do People Choose Compassion?}

The present studies modeled these same free choice methods to advance the debate about the nature of compassion. These studies address a new question: When and why do people avoid compassion compared to alternative courses of action (such as empathy and objective detachment)? This question addresses the phenomenal nature of compassion as well as the scientific and ethical debates about the relative merits of different responses to the suffering of 
others (compassion, empathy). Our work is among the first to directly contrast how people choose to relate to compassion and empathy, extending the free choice logic used in the empathy selection task to a broader range of moral responses. Importantly, this work contributes to the methodological diversity with which researchers can test for claims about compassion as a moral emotion.

In Studies 1-5, we examined whether people spontaneously selected or avoided compassion over alternative courses of action — including objective detachment and empathyand whether preferences to choose or avoid compassion associated with perceptions of compassion as more or less cognitively costly. We address pivotal questions about the nature of compassion: Do people choose to engage in compassion for strangers when given the choice, and if so, why? From the perspective that compassion is an easier alternative to empathy (e.g., Bloom, 2017; Jordan et al., 2016; Singer \& Klimecki, 2014), one might expect that people would freely choose compassion when given the opportunity, and rate it as less cognitively taxing than alternative courses of action. On the other hand, from the perspective that compassion can be challenging to cultivate and require control and efficacy (e.g., Eisenberg et al., 1996; Goetz et al., 2010), one might expect that people would freely choose to avoid compassion, and rate it as more cognitively taxing.

Prior studies of compassion tend to examine this emotion using trait self-report measures (e.g., the Empathic Concern scale of the Interpersonal Reactivity Index; Davis, 1983), experimental inductions of compassion (e.g., Klimecki et al., 2013, 2014; Oveis et al., 2010), or with state compassion ratings (Västfjäll et al., 2014) as well as with physiological responses thought to reflect compassion (Stellar et al., 2012, 2015) in response to stimuli or during interpersonal interactions. Although each of these methods have advantages, the current 
approach affords multiple distinct benefits by comparison. Self-report measures of compassion may be susceptible to social desirability or inaccurate self-concepts (Batson, 2011), and so examining how people actively choose compassion or not may be a more sensitive test. Similarly, whereas experimental inductions of compassion compel people to experience an emotion, the free-choice approach used here allows for a different type of test: whether people control exposure to compassion in the first place. Furthermore, recent work (Rom et al., 2020) found that perceiving low autonomy for engaging in one task may increase perceptions of its opportunity costs (i.e., missing out on the value of another task; Kurzban et al., 2013) and subsequently increase felt effort. In order to examine the felt effort of compassion in a more naturalistic state, the free choice approach provides an opportunity to assess compassion regulation behaviors and how such regulation behaviors associate with motivations and values (Tamir, 2009). In the current studies, we examined whether people are motivated to avoid compassion, and if this is linked with cognitive costs. This method provides a novel approach for testing claims about perceived benefits and/or costs of compassion.

\section{Potential Boundary Conditions on Compassion Regulation}

Motivational accounts of empathy (Keysers \& Gazzola, 2014; Zaki, 2014) suggest that context matters for whether people regulate empathic emotions. In Studies 6-8, we examined two potential boundary conditions: social proximity and contextual immersion.

Social proximity. Compassion is thought to have evolved as a caregiving emotion (Blaffer Hrdy, 2011; Goetz et al., 2010; Marsh, 2019; Preston, 2013) that can build relationships (DeSteno, 2015) and be relevant for intergroup conflicts (Klimecki, 2019). Numerous studies have documented intergroup empathy gaps, with empathic outcomes reduced for suffering outgroup (vs. in-group) targets (e.g., Cikara et al., 2014; Gutsell \& Inzlicht, 2012). Such intergroup 
empathy deficits may be impacted by motivation, with some work finding that these deficits may change depending on one's beliefs about empathy's capacity (Schumann et al., 2014). This work follows from the theoretical framework that empathy for close (vs. distant) others might involve richer representations of the experiences of close others (Preston \& de Waal, 2002).

Similarly, but perhaps even more so, we might expect such intergroup choice effects for compassion. One important point distinguishing empathy and compassion is that the latter involves the provision of care and resources, and so may be sensitive to expected reciprocal benefit (DeSteno, 2015; Marsh, 2019). As noted by DeSteno (2015), social similarity cues might be useful heuristics to establish where it is most sensible to allocate compassionate concern, and as such, cues to similarity could motivate compassionate choices. Prior work reveals that inducing compassion can lead people to feel more similarity to targets in need (Oveis et al., 2010), and similarity inductions can in turn increase compassion (Valdesolo \& DeSteno, 2011). Extending beyond human targets, people are less likely to choose compassion for animals that are less (vs. more) phylogenetically similar (Miralles et al., 2019).

Although we might expect intergroup effects on compassionate outcomes, little work has examined how motivated emotion regulation might create such effects, much less whether any choice effects are linked to perceived cognitive effort. It might be expected that compassion for close others might feel less taxing and be approached rather than avoided. In discussions about the scope of compassion, a division is sometimes drawn between compassion for kin and friends and more diffuse compassion spread across inter-cultural and global targets (e.g., out-groups and humanity as a whole; Ekman, 2014; Roeser et al., 2018), which might be more difficult to cultivate (for discussion, see Ekman, 2014). There might simply be less representations of the 
experiences of distant or dissimilar others to work from as the basis for empathic processes, with compassion included (Preston \& de Waal, 2002).

In Studies 6 and 7, we test social proximity as a boundary condition, with the expectation that although people would avoid compassion for strangers, they would choose compassion more often for close others, and that this would associate with changes in felt cognitive costs. These studies are among the first to examine whether and how motivated emotion regulation creates intergroup compassion gaps, in conjunction with felt effort, and we generalized this contrast for compassion against empathy (Study 6) and objective detachment (Study 7).

Contextual immersion. For the majority of the studies here, we used the empathy selection task as a repeated-trial, behavioral measure of compassion regulation. In order to capture sequential choices to generate compassion and better isolate its perceived effort costs, the task removed detailed context about the nature of the target, or the suffering involved (although in Studies 6-7 we did add the suffering cause and stipulated the target relationship). One drawback to this approach is that it did not allow for more enriched and immersive presentation of a single target of compassion. When more contextual details are provided, this can lead to more engaged and sometimes different responses (e.g., FeldmanHall et al., 2012). To examine whether people would opt to avoid compassion when presented with a more elaborately specified target, in Study 8 we used a different paradigm with audio stimuli drawing upon previous research in empathy and altruism (Shaw et al., 1994; Toi \& Batson, 1982).

\section{Overview of Studies}

Across studies, we adapted the empathy selection task (Cameron et al., 2019) to assess desire to feel compassion. In Studies 1 and 2, participants chose between a compassion deck and an objective detachment deck. In these studies, we assigned participants to complete a 
compassion version of the task (i.e., compassion vs. objectivity) or an empathy version (i.e., empathy vs. objectivity) in order to assess whether preferences to feel compassion and empathy differed. In Studies 3-5, we examined the contrast often posed in the literature (e.g., Bloom, 2017): when given the choice between compassion and empathy, which would people prefer?

In Studies 6-7, we examined whether relationship closeness influenced choice to feel compassion: Do people choose compassion more for close others than for distant others, and do any differences in choice preference associate with different felt costs and rewards? This approach allowed us to examine whether any preferences for compassion across Studies 1-5 would be shifted when focused on targets that may be more frequent and potentially relevant for compassionate responding — familiar kin or favorable targets. These studies also included methodological changes to strengthen inferences about compassion as measured in these studies, such as removing the need to write about feelings and including state compassion ratings to attempt to disentangle compassion and empathy choices in the task.

In Studies 1-7, our dependent variable was proportion of choosing compassion across trials, which served as our measure of compassion propensity. After completing the choice task, participants completed items from the NASA Task Load Index (Hart \& Staveland, 1988) to provide ratings of felt cognitive work for each deck. We used this measure to examine whether compassion was perceived as entailing more or less cognitive work than empathy and objectivity, and whether these cognitive costs associated with preferences to avoid compassion.

Finally, Study 8 aimed to generalize the findings from the Studies 1-7 beyond the empathy selection task to a more immersive context. Participants were instructed to listen to two different radio broadcasts in which strangers described their suffering (Shaw et al., 1994; Toi \& Batson, 1982), under compassion and objective detachment instructions, and given the option of 
escaping the broadcasts at the halfway point or continuing to listen to them (see also Schumann et al., 2014). This final study differed from Studies 1-7 by only presenting one-shot choices to continue engaging with compassion and objectivity, while also providing a more contextually enriched setting with enhanced ecological validity and realism. This study more closely resembles the everyday exposures people have to compassionate pleas, while also representing the choice to simply escape from them. Removing repeated trials within this study lowers ability to examine decreases in persistence or willingness to engage with compassion over time (Lin et al., 2020), but aimed to improve the ecological representation of being faced with choosing compassion.

All studies were approved by the institutional review board. Studies 1-7 were not formally pre-registered, but Study 8 was pre-registered (see As Predicted link: https://aspredicted.org/4da6z.pdf). Data and syntax can be accessed at the Open Science Framework: https://osf.io/k25yr/.

\section{Studies 1-2: Do People Choose Compassion for Strangers?}

\section{Method}

Participants. Study 1 included 150 MTurk participants $\left(93\right.$ female, 57 male, $M_{\text {age }}=$ 36.04 years, $\left.S D_{\text {age }}=11.87\right)$ and Study 2 included 215 MTurk participants (148 female, 62 male, 2 other, 3 unreported, $M_{\text {age }}=40.45$ years, $\left.S D_{\text {age }}=12.65\right)$. These final samples excluded participants who skipped trials ( $n=2$ in Study 1, $n=8$ in Study 2 ) and who provided nonsense responses ( $n=1$ in Study 1 ). For our sensitivity analyses, we focus on the ability to detect preferences to feel compassion, or empathy, within each of two between-subjects conditions. Sensitivity analyses using G*Power 3.1 (Faul et al., 2009) suggest that for a one-sample two- 
tailed $t$ test, Study 1 and Study 2 had $80 \%$ power to detect effect sizes as small as $d=.23$ and $d=$ .19 , respectively. For details about samples, see Supplemental Materials.

Materials and Procedures. In both studies, participants were randomly assigned to either the compassion condition or the empathy condition. The difference across these conditions was in the nature of the choice task: in the compassion conditions participants chose between compassion and objective detachment, and in the empathy conditions participants chose between empathy and objective detachment. Thus, the empathy conditions in these first two studies served as replications of earlier work using the empathy selection task (Cameron et al., 2019). The primary difference across Studies 1 and 2 was in the instructions provided for generating compassion and empathy.

In the pre-task instructions, participants were told that they would complete a series of trials in which they would see two decks of cards. Participants were instructed that they should choose between the two decks, and depending on their choice, they would see a set of instructions paired with an image of a person. In both conditions, participants were told that if they chose the objective deck during the task, they should be detached and focus on the person's physical characteristics. In the compassion condition, participants were told that if they chose the compassion deck during the task, they would be told to feel compassion. In the empathy condition, participants were told that if they chose the empathy deck during the task, they would be told to feel empathy. For complete instructions, see the Supplemental Materials.

Participants completed 40 trials, on each trial making a choice between the decks. Across conditions in Studies 1 and 2, the objective deck was always on the left in red and labeled as "DESCRIBE". In the compassion conditions, the compassion deck was always on the right in blue labeled as "CARE", and in the empathy conditions, the empathy deck was always on the 
right in blue labeled as "FEEL". After making a choice on any trial, participants saw an image of a child refugee (i.e., a stranger, as in Cameron et al., 2019). In Study 1, if participants selected the objective deck they were instructed: "Look at the person in the picture, and try to notice details about this person. Objectively focus on the external features and appearance of this person. Please write one sentence describing the age and gender of this person.” Instructions were very similar for Study 2 except that the final line read "Write one sentence about this person's age and gender."

The instructions for the compassion and empathy decks differed between Studies 1 and 2 . In Study 1, if participants were in the compassion condition and selected the compassion deck they read: "Look at the person in the picture, and try to feel compassion for this person. Compassionately focus on the internal experiences and feelings of this person. Please write one sentence describing how you want to care for this person." In Study 1, if participants were in the empathy condition and selected the empathy deck they read: "Look at the person in the picture, and try to feel what this person is feeling. Empathically focus on the internal experiences and feelings of this person. Please write one sentence describing the experiences and feelings of this person."

In Study 2, we changed the instructions to more closely match the compassion and empathy decks, such that they both called for writing about feelings but only differed in which emotion should be generated. We used instructions from prior work comparing compassion and empathy meditation (Klimecki et al., 2014), to better match the current work to prior comparisons of these emotions.

If participants were in the compassion condition and selected the compassion deck they read: "Look at the person in the picture, and try to feel compassion for this person. Generate 
warm feelings and caring for this person. Write one sentence describing these feelings." If participants were in the empathy condition and selected the empathy deck they read: "Look at the person in the picture, and try to feel what this person feels. Share the suffering and experiences of this person. Write one sentence describing these feelings." In all studies, trials were randomized and a timer prevented participants from submitting written responses until 10 seconds had elapsed.

After the task, participants completed open-ended responses about their performance (see Supplemental Materials). Subsequently, participants rated cognitive effort for each deck $^{1}$ using questions adapted from the NASA Task Load Index (Hart \& Staveland, 1988): "How mentally demanding was this deck?" "How hard did you have to work to accomplish your level of performance with this deck?" "How insecure, discouraged, irritated, stressed, and annoyed were you by this deck?" "How successful were you in accomplishing what you were asked to do in this deck?” As in prior work (Cameron et al., 2019), the first two questions correspond to felt effort, the third question to aversion, and the fourth question to efficacy/success. For details about individual difference and demographic measures, see the Supplemental Materials.

\section{Results and Discussion}

Compassion choice. First, we examined whether participants in the compassion conditions showed preferences to choose or avoid compassion by contrasting the proportion of compassion choice against chance (.50) in Studies 1 and 2. As shown in Table 1 and Figure 1, participants in the compassion conditions preferred to avoid compassion, choosing the compassion deck $25.89 \%$ of the time $(S D=.24)$ in Study $1, t(72)=-8.66, p<.001,95 \%$ CI of

\footnotetext{
${ }^{1}$ In Study 1, there was a typo in the NASA Task Load Index instructions such that regardless of condition (empathy, compassion) when participants made effort ratings about the deck on the right it was referred to as "Feel". Because of the between-subjects manipulation and constant position of the deck in the empathy selection task (i.e., Care on right in the compassion condition), we do not consider this to be an issue.
} 
the $M_{\text {diff }}$ from .50 [-.30, -.19], Hedges' $g=-1.00$; and $21.20 \%$ of the time $(S D=.25)$ in Study 2, $t(99)=-11.57, p<.001,95 \%$ CI $[-.34,-.24]$, Hedges' $g=-1.15$. Second, and replicating prior work (Cameron et al., 2019), participants in the empathy conditions preferred to avoid empathy, choosing the empathy deck $30.62 \%$ of the time $(S D=.28)$ in Study $1, t(76)=-5.98, p<.001$, $95 \%$ CI $[-.26,-.13]$, Hedges' $g=-.68$, and $29.46 \%$ of the time $(S D=.29)$ in Study $2, t(114)=-$ 7.71, $p<.001,95 \%$ CI [-.26, -.15], Hedges' $g=-.71$. Third, comparing across conditions, preferences to choose compassion and empathy did not differ in Study $1, F(1,148)=1.21, p=$ $.273,95 \%$ CI [-.13, .04], $\eta_{\mathrm{p}}{ }^{2}=.01$, but participants chose compassion somewhat less frequently than empathy in Study $2, F(1,213)=5.03, p=.026,95 \%$ CI $[-.16,-.01], \eta_{\mathrm{p}}^{2}=.02$, though this effect is small.

Table 1. Compassion choice in Studies 1-7.

\begin{tabular}{lcccccc}
\hline & $\begin{array}{c}\text { Compassion } \\
\text { Choice }\end{array}$ & $95 \%$ CI & & & & Hedges' \\
& $M(S D)$ & $M_{\text {diff }}$ & $t$ & $p$ & $N$ & $g$ \\
Study & $0.26(0.24)$ & {$[-0.30,-0.19]$} & -8.66 & $<.001$ & 73 & -1.00 \\
1. Compassion vs. Objectivity & $0.21(0.25)$ & {$[-0.34,-0.24]$} & -11.57 & $<.001$ & 100 & -1.15 \\
2. Compassion vs. Objectivity & $0.39(0.27)$ & {$[-0.17,-0.06]$} & -4.19 & $<.001$ & 98 & -0.42 \\
3. Compassion vs. Empathy & $0.42(0.29)$ & {$[-0.13,-0.02]$} & -2.94 & .004 & 123 & -0.26 \\
4. Compassion vs. Empathy & $0.18(0.17)$ & {$[-0.20,-0.11]$} & -7.43 & $<.001$ & 62 & -0.93 \\
5. Compassion vs. Emp. vs. Obj. & & & & & & \\
6. Compassion vs. Empathy & $0.46(0.21)$ & {$[-0.07,-0.01]$} & -2.73 & .007 & 183 & -0.20 \\
$\quad$ Close Others & $0.40(0.23)$ & {$[-0.13,-0.06]$} & -5.51 & $<.001$ & & -0.41 \\
$\quad$ Distant Others & & & & & & \\
7. Compassion vs. Objectivity & $0.62(0.26)$ & {$[0.08,0.16]$} & 6.21 & $<.001$ & 177 & 0.46 \\
$\quad$ Close Others & $0.44(0.28)$ & {$[-0.10,-0.02]$} & -2.83 & .005 & & -0.21 \\
$\quad$ Distant Others & & & & $<.001$ & $\mathbf{8 1 6}$ & $\mathbf{- 0 . 6 1}$ \\
Meta-analytic effect & & & & & & \\
\hline
\end{tabular}

Note. The meta-analytic effect excludes the close others conditions in Studies 6-7. The metaanalytic effect is Hedges' $g=-.61,95 \%$ CI [-.87, -.35], $Z=-4.64, p<.001$. 


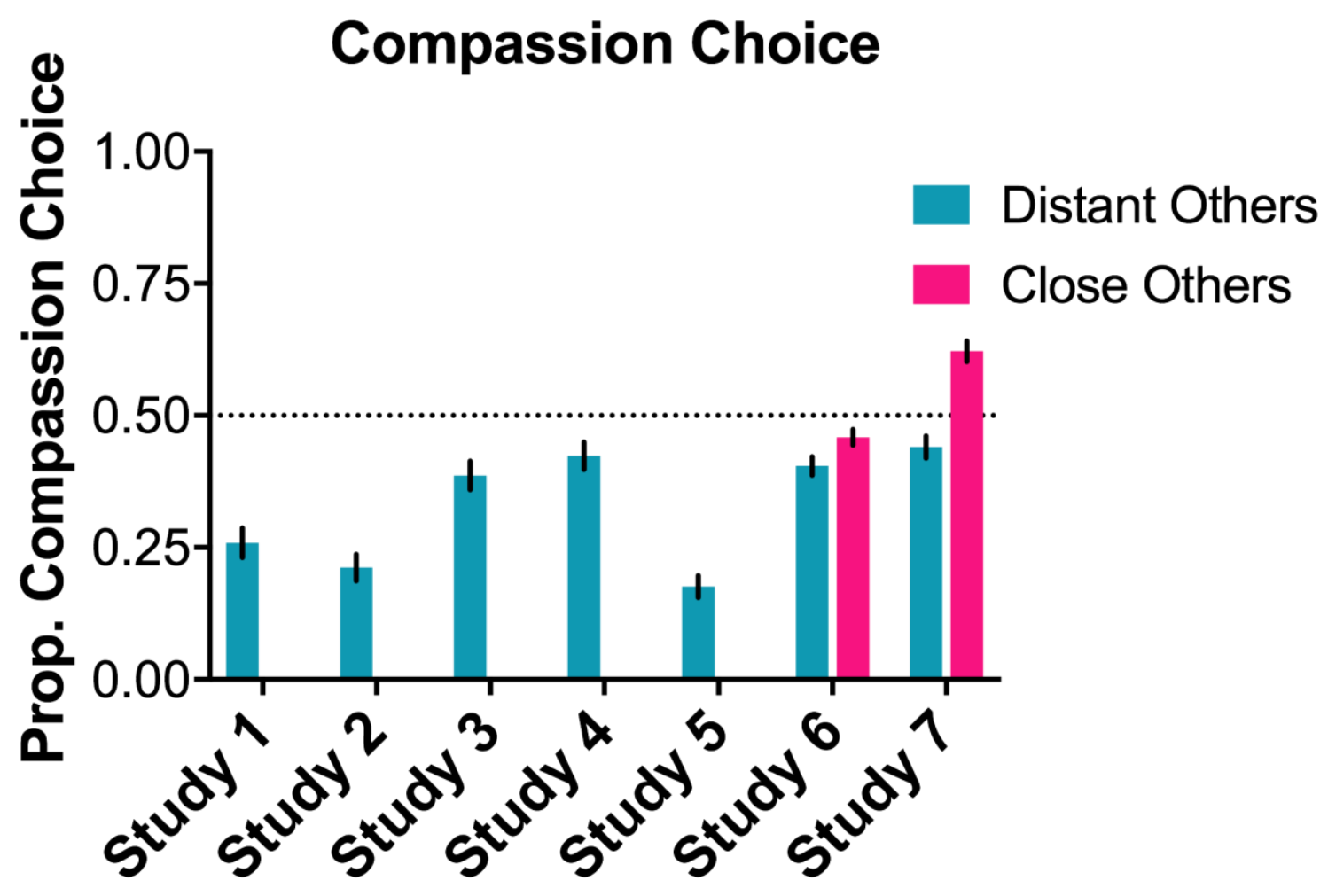

Fig. 1. Compassion choice across studies. The dotted line represents chance, against which compassion choice was contrasted in Studies 1-4 and 6-7; in Study 5, which had three deck options, chance was .333. Error bars reflect SE of the mean.

Cognitive costs. Participants preferred to avoid compassion - but why was this the case?

To examine this question, we examined differences in three cognitive cost measures-effort, aversion, and efficacy_across decks. The primary analyses focused on results within the compassion conditions of Studies 1 and 2. Tables 1-3 display results for each of these measures across Studies 1-7. Compared to the objective deck, participants rated the compassion deck as more effortful (Study 1: $F(1,72)=15.03, p<.001$, Hedges' $g=0.45 ;$ Study 2: $F(1,99)=35.74$, $p<.001$, Hedges' $g=0.64$ ), more aversive (Study 1: $F(1,72)=4.17, p=.045$, Hedges' $g=0.24$; Study 2: $F(1,99)=6.14, p=.015$, Hedges' $g=0.26)$, and less efficacious $($ Study 1: $F(1,72)=$ 14.99, $p<.001$, Hedges' $g=-0.51$; Study 2: $F(1,99)=29.25, p<.001$, Hedges' $g=-0.61)$. 
Table 1. NASA Task Load Index effort ratings, Studies 1-7.

\begin{tabular}{|c|c|c|c|c|c|}
\hline Study & $\begin{array}{c}\text { Compassion } \\
\text { Deck } \\
M(S D)\end{array}$ & $\begin{array}{c}\text { Contrast } \\
\text { Deck } \\
M(S D)\end{array}$ & $\begin{array}{c}\mathrm{M}_{\mathrm{diff}} \\
{[95 \% \mathrm{CI}]}\end{array}$ & $p$ & $\begin{array}{l}\text { Hedges' } \\
g\end{array}$ \\
\hline 1. Compassion vs. Objectivity & $3.43(1.26)$ & $2.89(1.13)$ & $0.54[0.26,0.82]$ & $<.001$ & 0.45 \\
\hline 2. Compassion vs. Objectivity & $3.57(1.13)$ & $2.82(1.20)$ & $0.75[0.50,0.99]$ & $<.001$ & 0.64 \\
\hline 3. Compassion vs. Empathy & $3.60(1.23)$ & $3.46(1.10)$ & $0.14[-0.04,0.32]$ & .133 & 0.12 \\
\hline 4. Compassion vs. Empathy & $3.74(1.06)$ & $3.76(1.05)$ & $-0.02[-0.15,0.11]$ & .754 & -0.02 \\
\hline $\begin{array}{l}\text { 5. Compassion vs. Emp. \& Obj. } \\
\text { 6. Compassion vs. Empathy }\end{array}$ & $3.48(1.12)$ & $2.98(0.97)$ & $0.50[0.29,0.71]$ & $<.001$ & 0.47 \\
\hline Close Others & $2.81(1.18)$ & $2.65(1.14)$ & $0.16[0.04,0.28]$ & .010 & 0.14 \\
\hline Distant Others & $2.86(1.18)$ & $2.68(1.10)$ & $0.18[0.05,0.32]$ & .008 & 0.16 \\
\hline 7. Compassion vs. Objectivity & & & & & \\
\hline Close Others & $2.64(1.14)$ & $2.54(1.18)$ & $0.10[-0.08,0.28]$ & .275 & 0.08 \\
\hline Distant Others & $2.72(1.19)$ & $2.32(1.18)$ & $0.40\left[\begin{array}{lll}0.22 & 0.58\end{array}\right]$ & $<.001$ & 0.34 \\
\hline Meta-analytic effect & & & & $<.001$ & 0.29 \\
\hline
\end{tabular}

Note for Tables 1-3. In Study 5, the ratings of the empathy and objective deck were collapsed and compared to the rating of the compassion deck. The close others conditions of Studies 6 and 7 were excluded from the meta-analysis for deck differences in costs. Meta-analytic estimates are from random-effects meta-analyses (Borenstein et al., 2009, 2013).

Table 2. NASA Task Load Index aversion ratings, Studies 1-7.

\begin{tabular}{lccccc}
\hline & $\begin{array}{c}\text { Compassion } \\
\text { Deck }\end{array}$ & $\begin{array}{c}\text { Contrast } \\
\text { Deck }\end{array}$ & $\begin{array}{c}\mathrm{M}_{\text {diff }} \\
{[95 \% \mathrm{CI}]}\end{array}$ & $p$ & Hedges' $g$ \\
\hline Study & $M(S D)$ & $M(S D)$ & $0.33[0.01,0.65]$ & .045 & 0.24 \\
\hline 1. Compassion vs. Objectivity & $3.00(1.41)$ & $2.67(1.33)$ & 0.015 & 0.26 \\
2. Compassion vs. Objectivity & $3.28(1.38)$ & $2.92(1.36)$ & $0.36[0.07,0.65]$ & .015 & \\
3. Compassion vs. Empathy & $3.33(1.31)$ & $3.21(1.29)$ & $0.11[-0.07,0.30]$ & .235 & 0.09 \\
4. Compassion vs. Empathy & $3.43(1.36)$ & $3.29(1.40)$ & $0.15[-0.03,0.33]$ & .106 & 0.11 \\
5. Compassion vs. Emp. \& Obj. & $3.11(1.26)$ & $2.88(1.13)$ & $0.23[-0.04,0.50]$ & .088 & 0.19 \\
6. Compassion vs. Empathy & & & & & \\
$\quad$ Close Others & $2.35(1.35)$ & $2.13(1.23)$ & $0.22[0.07,0.37]$ & .005 & 0.17 \\
$\quad$ Distant Others & $2.31(1.29)$ & $2.16(1.19)$ & $0.14[-0.02,0.30]$ & .077 & 0.11 \\
7. Compassion vs. Objectivity & & & & & \\
$\quad$ Close Others & $1.91(1.16)$ & $2.16(1.28)$ & $-0.25[-0.42,-0.09]$ & .003 & -0.21 \\
$\quad$ Distant Others & $2.05(1.24)$ & $1.97(1.19)$ & $0.07[-0.08,0.22]$ & .338 & 0.06 \\
Meta-analytic effect & & & & $<.001$ & $\mathbf{0 . 1 2}$ \\
\hline
\end{tabular}


Table 3. NASA Task Load Index efficacy ratings, Studies 1-7.

\begin{tabular}{lccccc} 
& $\begin{array}{c}\text { Compassion } \\
\text { Deck }\end{array}$ & $\begin{array}{c}\text { Contrast } \\
\text { Deck }\end{array}$ & $\begin{array}{c}\mathrm{M}_{\text {diff }} \\
{[95 \% \mathrm{CI}]}\end{array}$ & $p$ & Hedges' $g$ \\
\hline Study & $M(S D)$ & $M(S D)$ & -0.51 \\
\hline 1. Compassion vs. Objectivity & $3.37(1.29)$ & $3.96(0.92)$ & $-0.59[-0.89,-0.29]$ & $<.001$ & -0.001 \\
2. Compassion vs. Objectivity & $3.40(1.31)$ & $4.11(0.92)$ & $-0.71[-0.97,-0.45]$ & $<.001$ & -0.61 \\
3. Compassion vs. Empathy & $3.69(1.13)$ & $3.96(0.91)$ & $-0.27[-0.51,-0.02]$ & .037 & -0.26 \\
4. Compassion vs. Empathy & $3.53(1.17)$ & $3.75(1.01)$ & $-0.22[-0.39,-0.06]$ & .009 & -0.20 \\
5. Compassion vs. Emp. \& Obj. & $3.74(1.14)$ & $3.97(0.78)$ & $-0.23[-0.49,0.04]$ & .088 & -0.22 \\
6. Compassion vs. Empathy & & & & & \\
$\quad$ Close Others & $3.93(0.94)$ & $4.01(0.95)$ & $-0.08[-0.22,0.07]$ & .293 & -0.08 \\
$\quad$ Distant Others & $3.66(1.14)$ & $3.90(1.01)$ & $-0.25[-0.41,-0.08]$ & .003 & -0.23 \\
7. Compassion vs. Objectivity & & & & & \\
$\quad$ Close Others & $4.07(1.05)$ & $3.77(1.19)$ & $0.29[0.11,0.48]$ & .002 & 0.26 \\
$\quad$ Distant Others & $3.84(1.06)$ & $3.95(1.14)$ & $-0.12[-0.31,0.07]$ & .226 & -0.11 \\
Meta-analytic effect & & & & $<.001$ & $\mathbf{- 0 . 2 8}$ \\
\hline
\end{tabular}

We next examined whether these differences in perceived cognitive costs across decks associated with choosing compassion. As displayed in Table 4, although there were not consistent relationships for effort and aversion, participants did choose compassion more when they felt more efficacious at it (Study 1: $r=.36, p=.002$, Study 2: $r=.24, p=.015$ ). Thus, participants felt that compassion was more cognitively costly than objective detachment, and in particular, feeling less efficacious at compassion associated with choosing compassion less often. 
Table 4. Correlations of compassion choice with NASA Task Load Index ratings.

\begin{tabular}{lccccccc}
\hline & \multicolumn{2}{c}{ Effort } & \multicolumn{2}{c}{ Aversion } & \multicolumn{2}{c}{ Efficacy } \\
Study & $r$ & $p$ & $r$ & $p$ & $r$ & $p$ & $N$ \\
\hline 1. Compassion vs. Objectivity & 0.06 & .600 & -0.15 & .218 & 0.36 & .002 & 73 \\
2. Compassion vs. Objectivity & -0.13 & .186 & -0.10 & .302 & 0.24 & .015 & 100 \\
3. Compassion vs. Empathy & -0.25 & .014 & -0.08 & .460 & 0.51 & $<.001$ & 98 \\
4. Compassion vs. Empathy & 0.07 & .429 & -0.05 & .608 & 0.49 & $<.001$ & 122 \\
5. Compassion vs. Emp. \& Obj. & -0.17 & .179 & -0.08 & .558 & 0.49 & $<.001$ & 62 \\
6. Compassion vs. Empathy & & & & & & & \\
$\quad$ Close Others & -0.12 & .113 & -0.05 & .468 & 0.33 & $<.001$ & 183 \\
$\quad$ Distant Others & -0.23 & .002 & -0.12 & .098 & 0.31 & $<.001$ & \\
7. Compassion vs. Objectivity & & & & & & & \\
$\quad$ Close Others & -0.14 & .055 & -0.11 & .128 & 0.34 & $<.001$ & 177 \\
$\quad$ Distant Others & -0.28 & $<.001$ & -0.18 & .020 & 0.49 & $<.001$ & $\mathbf{8 1 5}$ \\
Meta-analytic effect & $\mathbf{- 0 . 1 3}$ & $\mathbf{. 0 1 0}$ & $\mathbf{- 0 . 1 2}$ & $<. \mathbf{0 0 1}$ & $\mathbf{0 . 4 1}$ & $<. \mathbf{0 0 1}$ & $\mathbf{8 1}$ \\
\end{tabular}

Note. For meta-analytic estimates, choice and costs were averaged across the within-subjects target manipulation in Studies 6 and 7.

In the empathy conditions, results largely replicated previous work (Cameron et al., 2019): participants rated the empathy deck as more effortful, aversive, and less efficacious than the objective deck, and perceiving the empathy deck as less efficacious associated with choosing the empathy deck less often. Across both studies, the cognitive costs of compassion and empathy appeared similar and associated similarly with choice behavior. These results contrast with the perspective that compassion is cognitively and emotionally easier than empathy (e.g., Bloom, 2017; Jordan et al., 2016). Participants avoided compassion for strangers, much as they avoided empathy for strangers, and reported that both entailed similar cognitive costs. Whereas these studies highlighted how preferences for compassion and empathy might be similar, in the next studies we examined how compassion and empathy might differ: when pit directly against each other, which do people prefer, and which do they rate as more challenging?

\section{Studies 3-5: Do People Prefer Compassion or Empathy?}

In the next three studies, we compared preferences for compassion and empathy against each other. Scientific and ethical debates about empathy and compassion have often focused on 
whether compassion is felt as a less costly and more sustainable alternative to empathy (see Bloom, 2017; Klimecki \& Singer, 2014). Although empathy and compassion may often intertwine - because empathy might either lead to compassion (Klimecki \& Singer, 2014) or be a constituent of it (Strauss et al., 2016) - they need not be (Batson, 2011), and the larger debate about how to foster effective prosocial engagement typically positions these options as two contrasting courses of action. The free choice approach provided by the empathy selection task is a viable means to test this contrast, by allowing participants to freely choose between them and seeing which they prefer. Rather than assuming that compassion is more or less costly than empathy, the current approach is to see what participants prefer to do when given the option, and to assess any related perceptions of cognitive costs. On one hand, if compassion is less psychologically costly than empathy, as some suggest (Bloom, 2017), then when given the choice between compassion and empathy, participants should ostensibly prefer compassion, and also rate it as less cognitively demanding. On the other hand, if compassion is challenging to cultivate and experience, then participants should prefer empathy over compassion, and rate compassion as more demanding. Alternatively, if participants view compassion and empathy as similar experiences, then participants should not prefer either option (i.e., choices resembling $50 \%$ chance). Whereas Studies 3 and 4 compared compassion and empathy, Study 5 reintroduced objective detachment as a third option to test whether changing the choice context would shift preferences for empathy over compassion.

\section{Method}

Participants. Study 3 included 98 MTurk participants (66 female, 32 male, $M_{\text {age }}=38.26$ years, $\left.S D_{\text {age }}=12.19\right)$, Study 4 included 122 MTurk participants (72 female, 48 male, 3 unreported, $M_{\text {age }}=42.09$ years, $\left.S D_{\text {age }}=14.82\right)$, and Study 5 included 62 MTurk participants (43 
female, 19 male, $M_{\mathrm{age}}=37.21$ years, $\left.S D_{\mathrm{age}}=11.71\right)$. These final samples excluded participants who skipped responses on the Empathy Selection Task ( $n=1$ in Study 3, $n=7$ in Study 4, $n=2$ in Study 5) and completed earlier studies in the sequence ( $n=2$ in Study 3, $n=5$ in Study 4, $n=$ 1 in Study 5). Sensitivity analyses using $\mathrm{G} *$ Power 3.1 suggest that for a one-sample two-tailed $t$ test, these studies had $80 \%$ power to detect effect sizes as small as $d=0.29, d=0.26$, and $d=$ 0.36, respectively (Faul et al., 2009), all of which are smaller than the average effect size in psychology (Richard et al., 2003). For details about samples, see Supplemental Materials.

Materials and Procedures. Across Studies 3 and 4, participants chose between a red empathy deck that was always on the left labeled "FEEL" and a blue compassion deck that was always on the right labeled "CARE". Pre-task and trial-level instructions were identical for Study 3 and Study 1, and for Study 4 and Study 2. In Study 5, participants chose between a red empathy deck that was always on the left labeled "FEEL", a green compassion deck that was always in the middle labeled "CARE", and a blue objective deck that was always on the right labeled "DESCRIBE". For full details about the instructions, see Supplemental Materials. After the task, participants completed post-task open-ended questions and the NASA Task Load Index. ${ }^{2}$ For details about individual difference and demographics, see the Supplemental Materials.

\section{Results and Discussion}

Compassion choice. In Studies 3 and 4, and as shown in Table 1 and Figure 1, participants preferred to avoid compassion, choosing the compassion deck $38.65 \%$ of the time

\footnotetext{
${ }^{2}$ In Study 3, there was a typo in the survey such that for some participants, the decks in the NASA Task Load Index were referenced as the one on the left being "Describe" and the one on the right being "Feel". This typo was partially corrected for remaining participants such that the deck on the right was labeled as "Care". Because the items instructed participants to answer with respect to the deck that was always on the right (i.e., compassion) or always on the left (i.e., empathy), we have opted to retain these ratings in overall analyses. Meta-analytic results for cost effects detailed below do not change substantially when omitting Study 3 NASA ratings from inclusion.
} 
$(S D=.27)$ in Study 3, $t(97)=-4.19, p<.001,95 \%$ CI [-.17, -.06], Hedges' $g=-.42$, and $42.38 \%$ of the time $(S D=.29)$ in Study $4, t(122)=-2.94, p=.004,95 \%$ CI $[-.13,-.02]$, Hedges' $g=-.26$. That is, people preferred empathy over compassion in both studies. In Study 5, when we reintroduced the objective deck as a third option, participants no longer preferred empathy over compassion, choosing the compassion deck $17.62 \%$ of the time $(S D=.17), t=-7.43, p<.001$, $95 \%$ CI of the $M_{\text {diff }}$ from .333 [-.20, -11], Hedges' $g=-.93$, and the empathy deck $20.24 \%$ of the time ( $S D=.18), t=-5.65, p<.001,95 \% \mathrm{CI}$ of the $M_{\text {diff }}$ from $.333[-.18,-.08]$, Hedges' $g=-.71$, with the clear preference being for the objective deck $(M=62.14 \%, S D=.26)$. Thus, in our first direct comparison of compassion and empathy for strangers, participants preferred empathy over compassion in Studies 3-4. Importantly, Study 5 reveals that this preference depends on the choice context and the opportunity costs of other options - expanding the choice set to include a less effortful option eliminated preferences for empathy over compassion as participants opted for the less effortful objective option.

Cognitive costs. To understand why people chose to avoid compassion in favor of empathy, we examined differences in the cognitive cost measures - effort, aversion, and efficacy - across decks. Tables 1-3 display results for each of these measures, and descriptive statistics of each effort cost for each deck across studies are in the Supplemental Materials. In Studies 3 and 4 which compared compassion and empathy, participants did not rate compassion as more effortful (Study 3: $F(1,97)=2.30, p=.133$, Hedges' $g=.12$; Study 4: $F(1,121)=0.10$, $p=.754$, Hedges' $g=-.02$ ) or aversive (Study 3: $F(1,97)=1.43, p=.235$, Hedges' $g=.09$; Study 4: $F(1,121)=2.65, p=.106$, Hedges' $g=.11$ ), but did report feeling less efficacious at compassion than empathy (Study 3: $F(1,97)=4.49, p=.037$, Hedges' $g=-.26$; Study 4: $F(1$, 121) $=7.02, p=.009$, Hedges' $g=-.20$ ). 
In Study 5, we compared each of the cognitive costs across the three decks. For effort, there was a main effect of deck type, $F(2,122)=21.62, p<.001, \eta_{\mathrm{p}}{ }^{2}=.26$, such that the compassion deck $(M=3.48, S D=1.12)$ was rated as more effortful than the objective deck $(M=$ 2.63, $S D=1.18), p<.001,95 \% \mathrm{CI}$ on difference in estimated marginal means [.46, 1.25], but not more effortful than the empathy deck $(M=3.34, S D=1.12), p=.314,95 \%$ CI $[-.08, .37]$. For aversion, there was also a main effect of deck type, $F(2,122)=7.37, p=.001, \eta_{\mathrm{p}}^{2}=.11$, such that the compassion $\operatorname{deck}(M=3.11, S D=1.26)$ was rated as more aversive than the objective deck $(M=2.60, S D=1.34), p=.026,95 \%$ CI $[.05, .98]$, but not more than the empathy $\operatorname{deck}(M=3.16, S D=1.28), p=.970,95 \%$ CI $[-.34, .25]$. Finally, for efficacy, there was a main effect of deck type, $F(2,122)=4.95, p=.009, \eta_{\mathrm{p}}^{2}=.08$, such that the compassion deck $(M=$ 3.74, $S D=1.14)$ was rated as less efficacious than the objective deck $(M=4.16, S D=.89), p=$ $.024,95 \%$ CI $[-.80,-.04]$, but not less than the empathy deck $(M=3.77, S D=1.05), p=.995$, $95 \%$ CI $[-.39, .32]$. For the sake of examining how deck differences between compassion and comparison decks associated with compassion choice, we averaged cognitive costs of the empathy and objective decks. Tables 1-3 display deck comparisons between the compassion deck and the empathy/objective composite on each of the cognitive costs.

In summary, when contrasting compassion and empathy directly on cognitive costs, participants felt less successful at generating compassion than empathy in Studies 3 and 4, with no differences in effort or aversion. In Study 5, the effect for efficacy changed, as compassion and empathy were both seen as less efficacious than objective detachment, but were not rated as different from each other in efficacy. It may be that in this three-deck context, the opportunity costs of a much easier option (i.e., detachment) minimized apparent cost differences between compassion and empathy, mirroring the changed choice preferences. Much as participants no 
longer showed the deck preference for empathy over compassion when the third, easier objective deck was introduced, so they may have focused less on differences in efficacy between compassion and empathy, but rather how both were less efficacious than objectivity.

Importantly, across Studies 3-5 and as shown in Table 4, felt efficacy at compassion (compared to empathy in Studies 3 and 4, or empathy and objectivity in Study 5) associated with choosing compassion more often (Study 3: $r=0.51, p<.001$; Study 4: $r=0.49, p<.001$; Study 5: $r=0.49, p<.001)$. Replicating Studies 1 and 2, when participants felt that they were less successful at compassion, they were less likely to want to care for others. In sum, participants preferred to feel empathy rather than compassion in response to strangers, and this preference associated with perceiving compassion to be a difficult feeling to generate.

\section{Studies 6-7: Do People Prefer Compassion for Close Others?}

In Studies 1-5, participants preferred to avoid choosing compassion, whether the contrast was objective detachment or empathy, and this preference associated with perceptions that compassion was cognitively costly_-specifically, when they felt inefficacious at generating it. However, it may be that social proximity provides an important boundary condition on compassion avoidance. In Studies 6-7, we examined whether participants would choose compassion more for close others than distant others, and whether any choice difference would associate with differences in felt cognitive costs and rewards.

Additionally, to address the concern that participants are avoiding verbal description of compassion, rather than compassion itself, we adapted the task so that no verbalization of compassion was required. Lastly, we assessed self-reported feelings of arousal, valence, and concern to examine whether participants actually increased their feelings of concern when they chose to feel compassion for targets over the alternatives of empathy (Study 6) and objective 
detachment (Study 7). Doing so allowed a test of whether participants were avoiding compassion per se instead of mundane features of the task, and also to test whether choosing compassion would increase state feelings of compassionate concern —-thus operating as a manipulation check of the compassion choice instructions in the task. If participants report higher levels of state concern on trials in which they choose compassion (instead of empathy), this provides additional evidence that participants are able to disentangle compassion from empathy, strengthening inferences about related cognitive costs.

\section{Methods}

Participants. Study 6 included 183 MTurk participants $\left(74\right.$ male, 109 female, $M_{\text {age }}=$ 36.73 years, $S D_{\text {age }}=10.95$ ). Study 7 included 177 MTurk participants ( 84 male, 93 female, $M_{\text {age }}$ $=36.57$ years, $\left.S D_{\text {age }}=11.03\right)$. These final samples excluded participants who completed the survey twice ( $n=3$ in Study 6, $n=7$ in Study 7), did a prior study in the project sequence ( $n=2$ in Study 6, $n=4$ in Study 7), did not follow task instructions to input the names of close and distant others ( $n=11$ in Study 6, $n=8$ in Study 7), and did not fully respond to the state affect items in the Empathy Selection Task ( $n=2$ in Study 6, $n=3$ in Study 7). Sensitivity analyses using $G *$ Power 3.1 (Faul et al., 2009) suggest that given the sample sizes of these studies, we have $80 \%$ power to detect effect sizes as small as $d=.21$ (in both studies) comparing compassion choice for close and distant others in a paired-samples t-test. For details about samples and additional individual difference and demographic measures, see Supplemental Materials.

Materials and Procedures. Participants were first asked to input the name of someone with whom they had a close relationship with as well as someone with whom they had a distant relationship (adapted from Kumashiro \& Sedikides, 2005; for a similar approach, see Ferguson et al., 2020). Specifically, participants were instructed: "Please think of a person that you have a 
warm and positive relationship with (e.g., a family member). Please write down the first and last name of this person." Participants were then asked to "Please think of a person that you know but only have a minimal relationship with (e.g., an acquaintance). Please write down the first and last name of this person." For both of these people, participants were also asked to "Please write down the nature of the relationship you have with this person."

After inputting the names of these two individuals, participants were told that they would see the name of one these two people, as well as hypothetical events that could happen to them. The names were piped in from the text that participants entered at the start of the task and paired with a mild misfortune (e.g., "[entered name] sat in gum on a park bench"; Bruneau et al., 2015; for details, see Supplemental Materials). During the choice task, participants were asked to make choices between two decks. In Study 6, choices were between a red deck labeled "FEEL" (i.e., empathy) and a blue deck labeled "CARE" (i.e., compassion). In Study 7, choices were between a red deck labeled "DESCRIBE" (i.e., objective detachment) and a blue deck labeled "CARE" (i.e., compassion). In these two studies, the deck sides were counterbalanced between each trial to rule out habituation to the assigned deck sides. Unlike in prior studies, participants did not input any text to describe their feelings but instead were instructed to advance to the next trial once they felt that they had achieved the given deck's directions. Participants were unable to advance until at least 5 seconds had elapsed.

In both studies, if participants chose the compassion deck they were instructed: "Think about this person, and try to feel compassion for them. Generate warm feelings and caring for this person. Once you have generated COMPASSION, press continue." In Study 6, if participants chose the empathy deck they were instructed: "Think about this person, and try to feel what this person feels. Share the feelings and experiences of this person. Once you have 
generated EMPATHY, press continue." In Study 7, if participants chose the objective deck they were instructed: "Think about this person, and try to be objective toward them. Focus on external details of what is happening to this person. Once you have become OBJECTIVE, press continue.” After completing the chosen deck's instructions on each trial, participants made arousal, valence, and concern ratings. Specifically, participants were asked "How calm/aroused do you currently feel?" (1-calm to 9-aroused), "How negative/positive do you currently feel?" (1-negative to 9-positive), and "How concerned are you for (the close other name or distant other name displays here)?" (1-not at all concerned to 9-extremely concerned) using selfassessment manikins (Bradley \& Lang, 1994; Dziobek et al., 2008). We included these ratings to examine whether participants felt more concern when choosing to feel compassion for targets, but also to determine whether participants reasonably distinguished between instructions to feel compassion against alternatives. Participants completed two counterbalanced blocks (close others, distant others) of 16 trials each, for a total of 32 choice trials. The same 16 events were used in both blocks.

After each block, participants completed a post-task questionnaire and questions about cognitive effort from the NASA Task Load Index. In these studies, participants also completed two exploratory questions measuring perceived reward ("How emotionally rewarding was this deck?" "How socially rewarding was this deck?") and one question measuring perceived value (“How valuable did you find this deck?”) for each deck within the given block. For details about additional individual difference and demographic measures, see the Supplemental Materials.

\section{Results and Discussion}

Compassion choice. As displayed in Table 1 and Figure 1, participants were more likely to choose compassion for close others than for distant others (Study 6: $F(1,182)=10.29, p=$ 
$.002,95 \%$ CI $[.02, .09], \eta_{\mathrm{p}}{ }^{2}=.05$; Study $\left.7: F(1,176)=80.85, p<.001, \eta_{\mathrm{p}}{ }^{2}=.31\right)$. For distant others, results replicated earlier studies, with participants choosing to avoid compassion (Study 6: $M=40.47 \%, S D=.23, t(182)=-5.51, p<.001,95 \%$ CI [-.13, -.06], Hedges' $g=-0.41$; Study 7: $M=44.03 \%, S D=.28, t(176)=-2.83, p=.005,95 \%$ CI [-.10, -.02], Hedges' $g=-.21)$. For close others, this avoidance effect weakened or reversed. In Study 6, with the compassionempathy contrast, participants avoided compassion but to a lesser extent than for distant others $(M=45.87 \%, S D=.21, t(182)=-2.73, p=.007,95 \%$ CI [-.07, -.01], Hedges' $g=-.20)$; in Study 7, with the contrast between compassion-objectivity contrast, participants showed a reversal, choosing to approach rather than avoid compassion $(M=62.18 \%, S D=.26, t(176)=6.21, p<$ $.001,95 \%$ CI $[.08, .16]$, Hedges' $g=0.46)$. In summary, participants were more willing to choose compassion for close others, revealing an important boundary condition on compassion avoidance. The strongest effect of the manipulation occurred when objective detachment was the contrast rather than empathy, possibly because empathy can be a viable response to suffering of close others, whereas being detached may seem less desirable.

State affect and concern ratings. Next, we examined the degree to which choosing compassion influenced ratings of valence, arousal, and concern, also modeling the interaction with target type (close, distant). For these analyses, we conducted multilevel models using SPSS MIXED, nesting trials within participants. Because target type was blocked and randomized, confounding target type with timing, we opted against modeling the repeated measures aspect of the design for the interaction test. ${ }^{3}$ Details of these analyses are in Tables 5 and 6. In Study 6, choosing the compassion (vs. empathy) deck was not linked with differences in arousal ( $p=$

\footnotetext{
${ }^{3}$ In auxiliary analyses which model time as a repeated measure with an autoregressive covariance structure (and coding time to reflect trials 1-32, such that for some participants trials 1-16 reflect close others and for others these trials reflect distant others, and vice versa for trials 17-32), results for the Target x Choice interactions in Studies 6 and 7 are statistically similar in terms of fixed effects and paired comparisons between estimated marginal means.
} 
$.816)$ or valence $(p=.141)$, but was associated with increased concern $(p<.001)$. There were no interactions of deck choice with target type ( $p$ s $>.320$ ). When participants chose compassion (over empathy), they did not report differences in state affect but did report greater concern. This result provides a manipulation check: choosing compassion (instead of empathy) led participants to feel more concern for the target they were focused on. Participants had different levels of state concern when choosing compassion instead of empathy, which suggests that the directions participants were provided, when chosen, led to different compassion responses within the context of the task.

In Study 7, with the contrast between compassion and objective detachment, there were significant effects for deck type, target type, and the target $\mathrm{x}$ deck interaction $(p s<=.001)$. Participants reported higher levels of arousal, negative valence, and concern after choosing the compassion deck than after choosing the objective deck, and these differences were amplified on trials involving close others, suggesting parochial emotional responding in favor of close others. Across Studies 6 and 7, participants reported feeling more concern after choosing compassion thereby validating an important feature of the task: those who chose compassion felt more concern. Effects on valence and arousal depended upon whether the contrast deck was emotional (i.e., empathy) or not (i.e., objectivity). 
Table 5. Multilevel models for state affect and concern ratings, Studies 6-7.

\begin{tabular}{ccccc}
\hline \multicolumn{1}{c}{ Study \& Outcome } & Effect & $F$ & df & $p$ \\
\hline Vtudy 6 & & & \\
Valence & Target & 131.91 & 5670.80 & $<.001$ \\
& Choice & 2.17 & 5731.79 & .141 \\
& Target*Choice & 0.51 & 5692.05 & .474 \\
Arousal & Target & 196.56 & 5670.68 & $<.001$ \\
& Choice & 0.05 & 5721.43 & .816 \\
& Target*Choice & 0.95 & 5688.14 & .330 \\
Concern & Target & 293.79 & 5670.83 & $<.001$ \\
& Choice & 78.11 & 5732.21 & $<.001$ \\
& Target*Choice & .51 & 5692.23 & .477 \\
Valence & Target & 89.15 & 5487.94 & $<.001$ \\
& Choice & 374.74 & 5565.53 & $<.001$ \\
& Target*Choice & 11.38 & 5508.56 & .001 \\
& & & \\
Arousal & Target & 154.31 & 5487.47 & $<.001$ \\
& Choice & 941.37 & 5558.95 & $<.001$ \\
& Target*Choice & 19.13 & 5506.26 & $<.001$ \\
& Target & 289.10 & 5489.75 & $<.001$ \\
Concern & Choice & 1512.50 & 5604.54 & $<.001$ \\
& & 17.28 & 5522.89 & $<.001$ \\
\hline & & &
\end{tabular}

Note. The table presents type III tests of fixed effects.

Table 6. Estimated marginal means from multilevel models, Studies 6-7.

\begin{tabular}{cllccc}
\hline Study \& Outcome & \multicolumn{1}{c}{ Target Type } & $\begin{array}{c}\text { Compassion } \\
\text { Deck } M(S E)\end{array}$ & $\begin{array}{c}\text { Contrast } \\
\text { Deck } M(S E)\end{array}$ & $p$ & 95\% CI Mdiff \\
\hline Study 6 & & & & & \\
Valence & Close Others & $4.40(.10)$ & $4.37(.10)$ & .561 & {$[-0.07,0.13]$} \\
& Distant Others & $4.84(.10)$ & $4.76(.10)$ & .125 & {$[-0.02,0.19]$} \\
Arousal & Close Others & $4.63(.13)$ & $4.58(.12)$ & .393 & {$[-0.07,0.17]$} \\
& Distant Others & $4.01(.13)$ & $4.04(.12)$ & .620 & {$[-0.15,0.09]$} \\
Concern & Close Others & $5.55(.12)$ & $5.09(.12)$ & $<.001$ & {$[0.33,0.59]$} \\
& Distant Others & $4.75(.13)$ & $4.36(.12)$ & $<.001$ & {$[0.26,0.53]$} \\
Study 7 & & & & & \\
Valence & Close Others & $4.25(.10)$ & $5.10(.10)$ & $<.001$ & {$[-0.95,-0.75]$} \\
& Distant Others & $4.68(.10)$ & $5.30(.10)$ & $<.001$ & {$[-0.72,-0.52]$} \\
Arousal & Close Others & $4.68(.13)$ & $3.10(.13)$ & $<.001$ & {$[1.45,1.70]$} \\
& Distant Others & $4.00(.13)$ & $2.78(.13)$ & $<.001$ & {$[1.09,1.33]$} \\
Concern & Close Others & $5.93(.11)$ & $3.68(.12)$ & $<.001$ & {$[2.11,2.39]$} \\
& Distant Others & $4.93(.11)$ & $3.09(.11)$ & $<.001$ & {$[1.71,1.99]$} \\
\hline
\end{tabular}


As an exploratory analysis, we examined whether trial-level ratings of valence, arousal, and concern changed over the course of the task. Because target type was counterbalanced across blocks, we estimated separate models for close others and distant others, focusing on each of the three ratings (concern, valence, and arousal). These were specified as linear mixed models with trials nested within participants, with random effects of intercept and slope for time, and an autoregressive covariance structure for within-subjects time. These models did not take into account participants' choices. In both Studies 6 and 7, state concern decreased over time, though this was not the case for distant others in Study 6 (Study 6 close others: $\mathrm{B}=-.02, \mathrm{SE}=.01, t=-$ $2.25, p=.026$, distant others: $\mathrm{B}=-.02, \mathrm{SE}=.01, t=-1.97, p=.050$; Study 7 close others: $\mathrm{B}=-$ $.04, \mathrm{SE}=.01, t=-4.94, p<.001$, distant others: $\mathrm{B}=-.03, \mathrm{SE}=.01, t=-3.34, p=.001)$. Valence changed over time, becoming more negative, in Study 7 (close others: $\mathrm{B}=-.02, \mathrm{SE}=.01, t=-$ 2.70, $p=.007$; distant others: $\mathrm{B}=-.02, \mathrm{SE}=.01, t=-2.61, p=.010$ ), but not Study 6 (close others: $\mathrm{B}=-.01, \mathrm{SE}=.01, t=-1.71, p=.089$; distant others: $\mathrm{B}=-.01, \mathrm{SE}=.01, t=-1.25, p=$ .212). Arousal did not change over time in either study (Study 6 close others: $\mathrm{B}=.00, \mathrm{SE}=.01, t$ $=.63, p=.528$; Study 6 distant others: $\mathrm{B}=-.01, \mathrm{SE}=.01, t=-.90, p=.371$; Study 7 close others: $\mathrm{B}=-.00, \mathrm{SE}=.01, t=-.29, p=.775$; Study 7 distant others: $\mathrm{B}=.00, \mathrm{SE}=.01, t=.10, p$ $=.924)$. Thus, in both studies, state levels of compassionate concern became weaker as participants completed more trials of the empathy selection task.

Cognitive costs. Studies 1-5 suggest that differences in cognitive costs, particularly efficacy, may explain compassion choice differences. We examined differences in felt costs and reward across decks, modeling the interaction with target type. Tables 1-3 display descriptive and inferential statistics for effort, aversion, and efficacy, and Tables 7-8 display these for the deck ratings of reward and value which were additions to these studies. 
Table 7. Reward ratings for compassion and contrast decks, Studies 6 and 7.

\begin{tabular}{|c|c|c|c|c|c|}
\hline Study & $\begin{array}{c}\text { Compassion } \\
\text { Deck } \\
M(S D)\end{array}$ & $\begin{array}{l}\text { Contrast } \\
\text { Deck } \\
M(S D)\end{array}$ & $\begin{array}{c}M_{\mathrm{diff}} \\
{[95 \% \mathrm{CI}]}\end{array}$ & $p$ & Hedges' $g$ \\
\hline \multicolumn{6}{|c|}{ 6. Compassion vs. Empathy } \\
\hline Close Others & $2.92(1.01)$ & $2.87(1.09)$ & $0.05[-0.07,0.18]$ & .405 & 0.05 \\
\hline Distant Others & $2.68(1.08)$ & $2.61(1.08)$ & $0.06[-0.05,0.17]$ & .259 & 0.06 \\
\hline \multicolumn{6}{|c|}{ 7. Compassion vs. Objectivity } \\
\hline Close Others & $3.27(1.19)$ & $2.42(1.21)$ & $0.85[0.66,1.04]$ & $<.001$ & 0.70 \\
\hline Distant Others & $2.98(1.20)$ & $2.45(1.15)$ & $0.53[0.36,0.69]$ & $<.001$ & 0.44 \\
\hline
\end{tabular}

Table 8. Value ratings for compassion and contrast decks, Studies 6 and 7.

\begin{tabular}{lccccc} 
& $\begin{array}{c}\text { Compassion } \\
\text { Deck }\end{array}$ & $\begin{array}{c}\text { Contrast } \\
\text { Deck }\end{array}$ & $\begin{array}{c}\mathrm{M}_{\text {diff }} \\
{[95 \% \mathrm{CI}]}\end{array}$ & $p$ & Hedges' $g$ \\
\hline Study & $M(S D)$ & $M(S D)$ & & & \\
\hline 6. Compassion vs. Empathy & & & & \\
$\quad$ Close Others & $3.13(1.12)$ & $3.11(1.11)$ & $0.02[-0.12,0.16]$ & .760 & 0.02 \\
$\quad$ Distant Others & $2.81(1.17)$ & $2.98(1.19)$ & $-0.17[-0.30,-0.05]$ & .007 & -0.15 \\
7. Compassion vs. Objectivity & & & & & \\
$\quad$ Close Others & $3.36(1.24)$ & $2.67(1.22)$ & $0.68[0.48,0.89]$ & $<.001$ & 0.55 \\
$\quad$ Distant Others & $3.07(1.27)$ & $2.74(1.18)$ & $0.33[0.13,0.52]$ & .001 & 0.27 \\
\hline
\end{tabular}

In Study 6, participants reported that the compassion deck (vs. empathy deck) was more effortful, $F(1,182)=10.50, p=.001, \eta_{\mathrm{p}}{ }^{2}=.05,95 \%$ CI $[.07, .28]$, more aversive, $F(1,182)=$ $8.52 p=.004, \eta_{\mathrm{p}}{ }^{2}=.04,95 \%$ CI $[.06, .30]$, and less efficacious, $F(1,182)=8.92, p=.003, \eta_{\mathrm{p}}{ }^{2}=$ $.05,95 \%$ CI [-.27, -.05], but did not report differences in reward, $F(1,182)=1.66, p=.199, \eta_{\mathrm{p}}{ }^{2}$ $=.01,95 \% \mathrm{CI}[-.03, .15]$, or value, $F(1,182)=2.38, p=.125, \eta_{\mathrm{p}}{ }^{2}=.01,95 \% \mathrm{CI}[-.17, .02]$. There were no target $\mathrm{x}$ deck interactions for effort, $F(1,182)=.09, p=.770$, aversion, $F(1,182)$ $=.63, p=.430$, efficacy, $F(1,182)=2.33, p=.128$, or reward, $F(1,182)=.01, p=.919$.

However, a target $\mathrm{x}$ deck interaction emerged for value, $F(1,182)=4.46, p=.036, \eta_{\mathrm{p}}{ }^{2}=.02$ : participants valued compassion less than empathy for distant others, $F(1,182)=7.36, p=.007$, $\eta_{\mathrm{p}}^{2}=.04$, Hedges' $g=-.15$, but not for close others, $F(1,182)=.09, p=.760, \eta_{\mathrm{p}}^{2}=.00$, Hedges' $g=.02$. Similar to the state concern ratings, participants perceived increasing levels of cognitive 
effort when trying to feel compassion over empathy, suggesting that participants separated these two emotional states on their cognitive effort demands.

In Study 7, participants reported that the compassion deck (vs. objective deck) was more effortful, $F(1,176)=12.60, p<.001, \eta_{\mathrm{p}}^{2}=.07,95 \%$ CI $[.11, .39]$, valuable, $F(1,176)=37.84, p$ $<.001, \eta_{\mathrm{p}}{ }^{2}=.18,95 \%$ CI [.34. .67], and rewarding, $F(1,176)=75.09, p<.001, \eta_{\mathrm{p}}{ }^{2}=.30,95 \%$ CI $[.53, .84]$. There were no deck differences in efficacy, $F(1,176)=1.31, p=.255, \eta_{\mathrm{p}}{ }^{2}=.01$, 95\% CI [-.06. .24], or aversion, $F(1,176)=2.81, p=.095, \eta_{\mathrm{p}}^{2}=.02,95 \%$ CI $[-.20, .02]$. However, unlike in Study 6, in Study 7 there were target $\mathrm{x}$ deck interactions for all measures, including effort, $F(1,176)=7.31, p=.008, \eta_{\mathrm{p}}{ }^{2}=.04$, aversion, $F(1,176)=7.73, p=.006, \eta_{\mathrm{p}}{ }^{2}=$ .04 , efficacy, $F(1,176)=12.77, p<.001, \eta_{\mathrm{p}}^{2}=.07$, value, $F(1,176)=8.57, p<.001, \eta_{\mathrm{p}}^{2}=.05$, and reward, $F(1,176)=15.60, p<.001, \eta_{\mathrm{p}}^{2}=.08$. The interactions all followed a similar pattern: when faced with close (vs. distant) others, relative effort costs of compassion were reduced, and potential rewards of compassion were increased. For distant others, participants rated the compassion deck (vs. objective deck) as more effortful, $F(1,176)=19.79, p<.001, \eta_{\mathrm{p}}{ }^{2}=.10$, Hedges' $g=.34$, more rewarding, $F(1,176)=41.72, p<.001, \eta_{\mathrm{p}}^{2}=.19$, Hedges' $g=.44$, and more valuable, $F(1,176)=10.76, p=.001, \eta_{\mathrm{p}}^{2}=.06$, Hedges' $g=.27$, with no differences for aversion, $F(1,176)=.92, p=.338, \eta_{\mathrm{p}}^{2}=.01$, Hedges' $g=.06$, or efficacy, $F(1,176)=1.48, p=$ $.226, \eta_{\mathrm{p}}^{2}=.01$, Hedges' $g=-.11$. By contrast, for close others, there was no more effort attributed to the compassion (vs. objective) deck, $F(1,176)=1.20, p=.275, \eta_{\mathrm{p}}^{2}=.01$, Hedges' $g$ $=.08$, but participants did rate the compassion deck as less aversive, $F(1,176)=9.34, p=.003$, $\eta_{\mathrm{p}}{ }^{2}=.05$, Hedges' $g=-.21$, and more efficacious, $F(1,176)=9.72, p=.002, \eta_{\mathrm{p}}{ }^{2}=.05$, Hedges' $g=.26$. Additionally, there were stronger deck effects for reward, $F(1,176)=77.58, p<.001$, $\eta_{\mathrm{p}}{ }^{2}=.31$, Hedges' $g=.70$, and value, $F(1,176)=42.78, p<.001, \eta_{\mathrm{p}}{ }^{2}=.20$, Hedges' $g=.55$. 
In terms of cognitive costs for distant others, compassion was rated as more effortful but not more aversive or less efficacious; by contrast, for close others compassion was not rated as more effortful and was rated as less aversive and more efficacious. In terms of rewards, compassion was rated as more rewarding and valuable regardless of target type, but these differences were stronger for close others than distant others.

Tables 4 (cognitive costs) and Table 9 (reward and value) present correlations of each of the cost/reward measures with compassion choice separately for each target type. The primary analysis of interest was whether differences in compassion choice across target type would associate with differences in perceived costs and rewards across target type. We created parochial bias scores for choice (i.e., compassion choice close others - compassion choice distant others) as well as each cost and reward measure (e.g., calculating this for efficacy: efficacy difference score close others - efficacy difference score distant others). Overall, parochial compassion choice was correlated with parochial target differences in felt effort and reward. Participants were more likely to choose compassion for close (vs. distant) others when they felt that compassion for close (vs. distant) others was more efficacious (Study 6: $r=.33, p<.001 ;$ Study 7: $r=.30, p<$ .001 ), more rewarding (Study 6: $r=.18, p=.016$; Study 7: $r=.19, p=.009$ ) and more valuable (Study 6: $r=.29, p<.001 ;$ Study 7: $r=.31, p<.001$ ), though this relationship varied for effort (Study 6: $r=-.11, p=.125 ;$ Study 7: $r=-.16, p=.029$ ) and was not present for aversion (Study $6: r=-.04, p=.586 ;$ Study $7: r=-.05, p=.521)$. 
Table 9. Correlations of compassion choice with ratings of reward and value.

\begin{tabular}{lccccc}
\hline \multicolumn{2}{c}{ Reward } & \multicolumn{3}{c}{ Value } \\
Study & $r$ & $p$ & $r$ & $p$ & $\mathrm{~N}$ \\
\hline 6. Compassion vs. Empathy & & & & & \\
$\quad$ Close Others & 0.12 & .102 & 0.23 & .002 & 183 \\
$\quad$ Distant Others & 0.12 & .096 & 0.26 & $<.001$ & \\
7. Compassion vs. Objectivity & & & & & \\
$\quad$ Close Others & 0.32 & $<.001$ & 0.32 & $<.001$ & 177 \\
$\quad$ Distant Others & 0.22 & .004 & 0.50 & $<.001$ & \\
\hline
\end{tabular}

In summary, participants chose compassion more often for close others than distant others and importantly experienced more concern for close (vs. distant) others after choosing to feel compassion over alternatives, even empathy. When participants felt that compassion for close (vs. distant) others involved less cognitive work and more reward, they were more likely to choose compassion in favor of close others.

\section{Interim Meta-Analyses of Studies 1-7}

In this section, we report results for meta-analyses of compassion choice in the empathy selection task, felt cognitive costs of compassion, and the relationship between the two. These relationships were examined across Studies 1-7 using random-effects meta-analyses (Borenstein et al., 2009). For the choice analysis and comparison of cognitive costs across decks, we excluded the close others conditions of Studies 6 and 7, in which compassion avoidance and cognitive costs were reduced. We made this analytic choice because we had expected that overall compassion avoidance and cognitive costs of compassion would be reduced in the close others conditions of these studies. When we were meta-analyzing the correlations between cognitive costs and compassion choice, we averaged across the within-subjects manipulation, such that we examined associations between overall compassion choice (collapsing across target condition) and each of the cognitive costs (collapsing across target condition), because cognitive costs were not expected to relate differently to compassion choice behavior depending on target type. 
Choosing compassion in the empathy selection task. The preference to avoid compassion was large and robust: across studies, participants chose to avoid compassion (standardized mean difference of compassion choice in Hedges' $g=-.61,95 \%$ CI [-.87, -.35], Z $=-4.64, p<.001)$. Figure 2 displays the meta-analytic forest plot across studies.

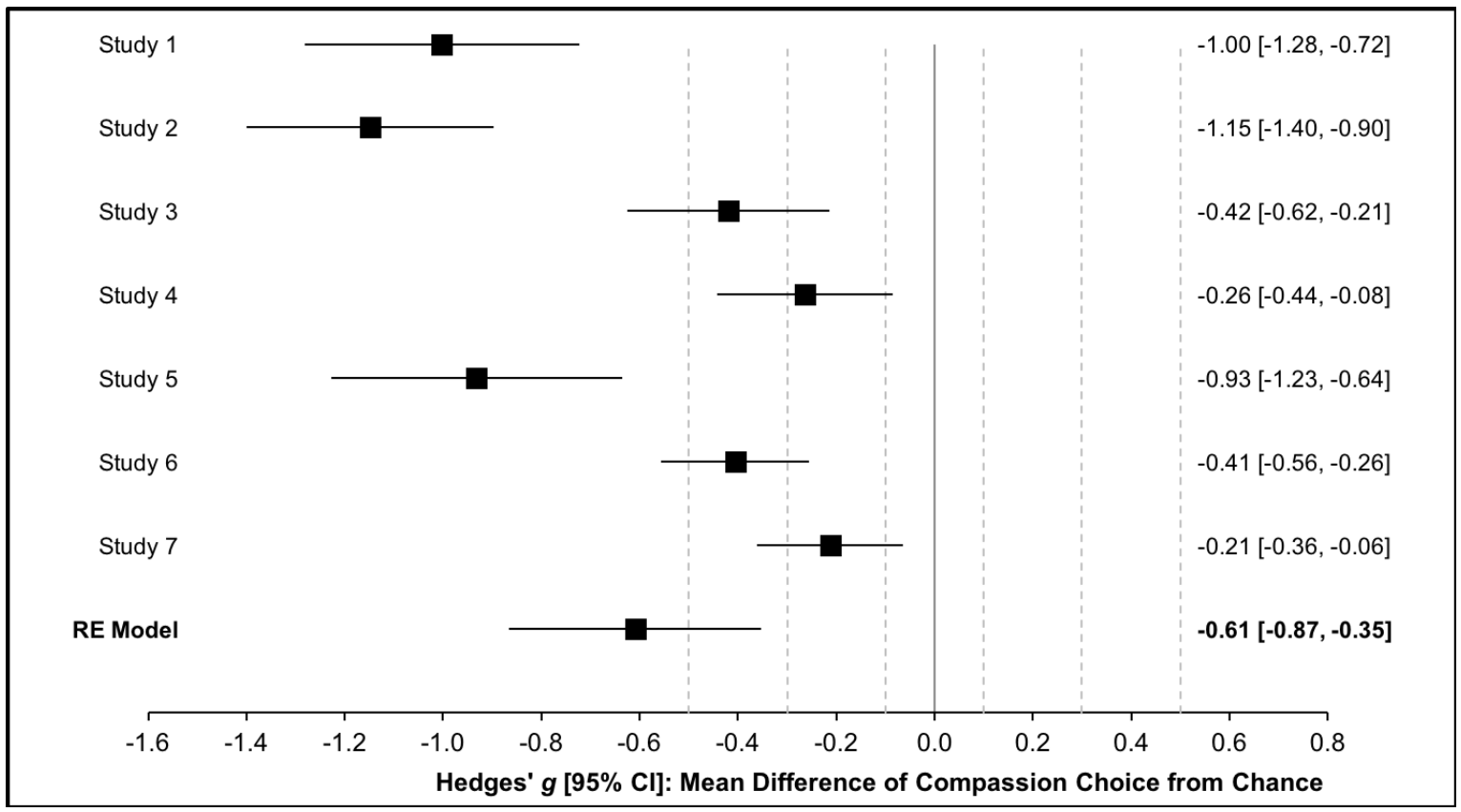

Figure 2. Meta-analytic forest plot of compassion choice across studies. The plot excludes close others conditions of Studies 6 and 7 because compassion avoidance was expected to be reduced.

In each of the studies, we were also able to assess whether choices to feel or avoid compassion changed over the duration of the empathy selection task. We conducted generalized linear mixed models in SPSS to understand the influence of time on probability of choosing compassion, with trials nested within participants. The model estimated a fixed effect for time (i.e., order of question, centered to start at 0 and end at one less than the maximum number of trials in a given study), and random effects for the intercept and time. Table 10 depicts model results and the meta-analytic estimate (excluding the close others conditions of Studies 6 and 7), which reveals a modest tendency for compassion choices to decline over time, although this 
effect was more notable in Studies 1-5 and not Studies 6-7, which could potentially be due to the fewer number of trials in each within-subject block of the latter studies.

Table 10. Influence of time course on probability of compassion choice.

\begin{tabular}{|c|c|c|c|c|c|c|}
\hline Study & $\mathrm{B}$ & SE & $t$ & $p$ & $\operatorname{Exp}(B)$ & $\begin{array}{l}95 \% \text { CI } \\
\operatorname{Exp}(\mathrm{B})\end{array}$ \\
\hline 1 & -.04 & .01 & -4.78 & $<.001$ & 0.97 & {$[0.95,0.98]$} \\
\hline 2 & -.06 & .01 & -7.74 & $<.001$ & 0.94 & {$[0.93,0.96]$} \\
\hline 3 & -.02 & .01 & -3.04 & .002 & 0.98 & {$[0.96,0.99]$} \\
\hline 4 & -.02 & .01 & -2.63 & .009 & 0.98 & {$[0.96,0.99]$} \\
\hline 5 & -.07 & .01 & -6.27 & $<.001$ & 0.93 & {$[0.92,0.95]$} \\
\hline $6_{\text {close }}$ & -.01 & .01 & -1.12 & .265 & 0.99 & {$[0.98,1.01]$} \\
\hline $6_{\text {distant }}$ & .00 & .01 & 0.38 & .701 & 1.00 & {$[0.99,1.02]$} \\
\hline $7_{\text {close }}$ & -.01 & .01 & -1.32 & .186 & 0.99 & {$[0.97,1.01]$} \\
\hline $7_{\text {distant }}$ & .02 & .01 & 1.87 & .061 & 1.02 & {$[1.00,1.04]$} \\
\hline Meta-analytic effect & -.03 & .01 & & .013 & 0.97 & {$[0.95,0.99]$} \\
\hline
\end{tabular}

Note. Results from generalized linear model predicting binary choice on each trial of empathy selection task, with coefficient corresponding to the log odds for the time effect and $\operatorname{Exp}(\mathrm{B})$ referring to the odds ratio. Meta-analysis excludes close others conditions of Studies 6-7.

Cognitive costs and compassion choice. Although it is important to test whether people choose to avoid compassion, an equally important question is why people have this preference. We predicted that cognitive costs of compassion would associate with compassion avoidance. Participants perceived compassion (vs. empathy or objectivity) as more effortful, Hedges' $g=$ $.29,95 \% \mathrm{CI}[.13, .45], Z=3.52, p<.001$, more aversive, Hedges' $g=.12,95 \% \mathrm{CI}[.06, .18], Z=$ $4.09, p<.001$, and less efficacious, Hedges' $g=-.28,95 \%$ CI $[-.41,-.16], Z=-4.57, p<.001$. Importantly, across studies participants chose compassion less often when they viewed it as more effortful, $r=-.13, Z=-2.57, p=.010$, and more aversive, $r=-.12, Z=-3.44, p<.001$, and chose compassion more often when they viewed it as more efficacious, $r=-.41, Z=-9.52, p<.001$. Figure 3 displays the relationship between compassion choice and each of these costs aggregated across studies. In contrast to claims that compassion is an easy alternative to empathy, here we 
found that participants avoided compassion for strangers, found it to be a cognitively challenging emotional experience, and that felt cognitive costs associated with compassion avoidance.
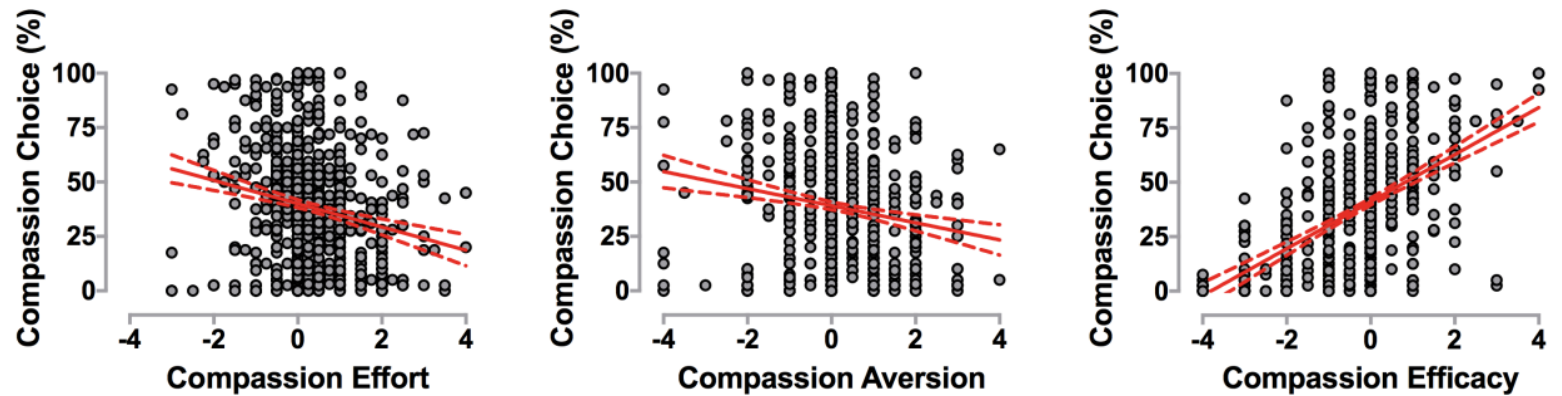

Figure 3. Associations of compassion choice with NASA Task Load Index ratings of effort, aversion, and efficacy, aggregated across Studies 1-7.

\section{Study 8: Escaping Immersive Compassion}

The first seven studies assessed compassion choice by adapting the empathy selection task. One advantage of this task is that it captures compassion regulation moment-to-moment, and over repeated instances. However, one potential drawback is that these studies did not provide enough contextual information about the individuals who were suffering, which might change how compassion is experienced. Affective science has often treated compassion as an emotional state which includes appraisals about costs and benefits, such as judgments of deservingness as well as coping resources to effectively help those who are suffering (DeSteno, 2015; Goetz et al., 2010). Therefore, contextual information around a person's suffering may change the costs of experiencing compassion for them. Additionally, although the repeated trials can provide more robust estimation of preferences to choose compassion, such an approach might be dissimilar to how compassion choices occur in everyday life for most people (with perhaps the exception of those who are repeatedly presented with suffering individuals, such as medical professionals; Figley, 2002). For instance, compassion regulation may involve a single decision to continue engaging with a compassion-inducing situation or not, such as a charitable 
news story or radio program. In everyday life, it may be more common for people to find themselves in compassion-inducing situations (e.g., interacting with a donation solicitor) and then decide whether to stay or leave.

In this final study, we aimed to use a more ecologically representative paradigm in which participants could opt to continue listening or not to audio broadcasts in which a target described a personal account of suffering (drawn from previous studies; Shaw et al., 1994; Toi \& Batson, 1982). This approach captures situation modification rather than situation selection (Gross \& Thompson, 2007), and is similar to ease-of-escape paradigms in the empathy-altruism literature (e.g., Batson et al., 1983; Schumann et al., 2014; for review see Batson, 2011). Participants in this final study only made two choices: of whether to modify the situation and escape listening when under compassion instructions, and again when under objective instructions. This approach constrained the number of choices to a one-shot decision for each condition, which increases immersion and realism, but may decrease the ability to observe the impact of effort costs on choices (Lin et al., 2020). However, this approach disentangled the relative choices between compassion and objectivity made in the empathy selection task in previous studies, allowing examination of choices in relation to each task in isolation (and also in comparison to each other). Finally, in this study we measured cognitive costs after an initial exposure to the stimuli but prior to choices of whether to continue, allowing us to test whether cognitive costs prospectively related to choices.

\section{Method}

Participants. Based on an a priori power analysis in $\mathrm{G}^{*}$ Power 3.1 for our repeated measures within-subject design, in order to adequately achieve $80 \%$ power to obtain a small-tomoderate effect size (e.g., $d=0.2$ ), we would need to obtain 52 participants (Faul et al., 2009). 
However, we were also aiming to recruit enough participants to test whether there was a correlation between cognitive effort and decisions to continue in each of the two conditions, as well as with the individual difference measures. To test for these correlations, an a priori power analysis in G*Power 3.1 for a small-to-medium correlation of $r=.20$ using a two-tailed test with 80\% power indicated that we would require 191 participants (Faul et al., 2009). Thus, we sought to recruit 200 participants from Amazon.com Mechanical Turk using TurkPrime (Litman et al., 2017) to also account for any participants who may leave the study (see

\section{https://aspredicted.org/4da6z.pdf).}

In Study 8, our final sample was 172 participants $\left(M_{\text {age }}=38.71, S D_{\text {age }}=11.82,1\right.$ unreported; 92 men, 74 women, 6 another gender identity). Of the 269 participants who started the survey, we excluded participants who did not complete the dependent measures (i.e., choice outcomes, NASA Task Load Index items, state affect and concern ratings; $n=66$ ), participants who indicated not attempting to follow the listening perspective instructions (responding " $1-\mathrm{Not}$ at all"; $n=6)$, participants who indicated that the audio clip did not play for them $(n=8)$, and participants who provided nonsense responses (i.e., random letters and numbers, nonsensical words) on our open-ended responses asking for the name of the person in the audio clip, their instructed listening perspective, and any thoughts they had about the broadcast programs within each condition $(n=17)$.

Listening task. Participants were provided with the following cover story: "This experiment is part of an ongoing pilot test for new programs for local radio stations. You will listen to and report your reactions to some available pilot recordings for each of the proposed programs. The programs are attempting a more personalized approach to news events." They then read (adapted from Shaw et al., 1994): 
All of the pilot recordings are based on real events, but none of the programs have been officially aired yet. As you listen to these programs, we are asking that you adopt a specific listening perspective while you hear each broadcast. We will present part of each broadcast program for you to listen to. We are trying to assess your evaluations of these broadcast programs at different stages. After you listen to each program, we will assess your evaluations of that program for future use. Press continue when you are ready for the first broadcast program.

After viewing this information, participants completed the primary dependent measure. In this paradigm, participants completed two trials in which they had the opportunity to continue with or exit from an audio stimulus describing personal suffering. In the within-subjects design, participants were randomly assigned to see the compassion or objective listening task first, which was then followed by the other task. The compassion and objectivity tasks were randomly paired with one of two edited audio clips from prior work (i.e., Carol Marcy, from Toi \& Batson, 1982; or Harold Mitchell, from Shaw et al., 1994), described in more detail below.

In the objective detachment listening task, participants were instructed to remain detached during the audio clip:

While you are listening to this broadcast, try to listen carefully to the information presented. Try to be as objective as possible, evaluating the information presented about the situation and about the person who is being interviewed. Concentrate on trying to listen objectively to the information being presented in this broadcast.

By contrast, in the compassion listening task, participants were instructed to generate feelings of compassion during the audio clip: 
While you are listening to this broadcast, try to feel compassion for the person being interviewed. Try to generate warm feelings for the person who is being interviewed, feeling caring concern for them. Concentrate on trying to feel compassion for the person being interviewed in the broadcast.

The content of the audio clips was counterbalanced in order and pairing with the compassion and objective detachment listening instructions. These clips were adapted from prior research (Shaw et al., 1994; Toi \& Batson, 1982)4, edited to remove location references and so that a comparable amount of time was spent across clips listening to the person being interviewed. This provided us with two approximately 2-minute long clips, each of which we split into two approximately 1minute halves. Before the Carol Marcy program, participants read a brief summary preamble:

Auto accidents continue to kill and maim Americans but the tragic impact of automobile accidents is often lost in the cold fact of statistics. Two were killed, four injured, and one is in critical condition. The reality of the tragedy implicit in such statements was brought home for Carol Marcy, a university student. She was riding in the car with her parents as they returned to their former home to visit friends. Recently, I talked with Carol about what happened next.

Before the Harold Mitchell program, participants read the following:

Harold Mitchell is 56 years old. He became homeless three years ago after losing his job because of an illness. His age and health problems have kept him from securing employment since then. He has no immediate family to assist him. What he needs is help in everyday type activities as well as some support in getting "back on his feet".

\footnotetext{
${ }^{4}$ We thank C. Daniel Batson for sharing the original audio materials that were adapted for use in this study.
} 
Participants were always reminded of their listening instructions before they went on to the program's first audio clip, and when they were on the audio clip screen, they were instructed to "Please ensure that your volume is turned on and that you have no other audio clips playing on your computer. On the next page, you will listen to the pilot radio program using an audio player. Press continue when you are ready to proceed." On the next page, participants read "Please ensure that your volume is turned on and that you have no other audio clips playing on your computer. Press the play button below to listen to the clip". For all audio clips within the survey, participants could see an audio player on screen that they could play and stop at any point, and then advance to the next screen.

Cognitive costs. After listening to the first 1-minute clip for each program, participants completed items from the NASA Task Load Index (Hart \& Staveland, 1988) as in previous studies. The items were adapted to be in reference to "the listening instructions for this program”. The reward and value items from Studies 6-7 were also included.

Escape paradigm. Our main dependent variable was whether participants chose to continue engaging with the audio program after listening to the first part. Participants read: "Thank you for listening to this radio broadcast program. Please indicate below whether you would like to continue listening to more of the radio broadcast program, or if you feel you have enough experience with the broadcast program to provide further evaluations." Participants could then choose between: "continue listening" or "do not continue listening". If participants selected to continue listening, they could listen to the second half of the audio clip, and then advanced to the state affect and concern ratings. If participants selected to not continue listening, they advanced directly to the state affect and concern ratings. 
State affect and concern ratings. Similar to Studies 6 and 7, participants then provided state affect and concern ratings: "How calm/aroused were you when listening to this program?" (1-calm; 9-aroused) "How negative/positive did you feel when listening to this program?" (1negative; 9-positive) "How concerned were you for Carol Marcy/Harold Mitchell?” (1-not at all; 9-extremely). As in Studies 6 and 7, the items were paired with the self-assessment manikin (Bradley \& Lang, 1999).

Attention check. After participants completed their state affect and concern ratings, participants then answered the following items: "Did the radio broadcast program audio that you were just presented with play?" (yes, no) "For our records, what was the name of the person in the last clip?" (open-ended) "What was the listening perspective that you were asked to take?" (open-ended) "To what extent did you attempt to follow the instructions about the listening perspective you were instructed to take on?" (1-Not at all; 7-Extremely) "In the space below, please let us know if you have any thoughts about this radio broadcast program" (open-ended essay).

Individual differences. After completing both the radio broadcast program evaluations, participants completed individual difference measures. Participants completed the ApathyMotivation Index (Ang et al., 2017), the Interpersonal Reactivity Index (Davis, 1983), the Empathy Index (Jordan et al., 2016), and an exploratory measure of lay theories of empathy and compassion. Participants then answered demographic questions as in previous studies. These measures are described in the Supplemental Materials.

\section{Results}

Choice to continue. In our first pre-registered analysis, we examined the descriptive statistics of choosing to continue within each of the two listening instruction conditions. 
Collapsing across counterbalanced program assignment (i.e., Carol Marcy or Harold Mitchell) and task order, participants were not very likely to opt to continue during either the compassion task $(M=15.70 \%, S D=.36$, for comparison against chance: $t(171)=-12.33, p<.001,95 \% \mathrm{CI}$ of the $\left.M_{\text {diff }}[-.40,-.29]\right)$ or the objective task ( $M=19.19 \%, S D=.39$, for comparison against chance: $t(171)=-10.23, p<.001,95 \%$ CI $[-.37,-.25])$. In an exploratory analysis, we found descriptive differences in choice to continue based on task order (Objective task first: Compassion $_{M}=11.11 \%$, Compassion $_{S D}=.32$, Objective $_{M}=28.89 \%$, Objective $_{S D}=.46$; Compassion task first: Compassion $_{M}=20.73 \%$, Compassion $_{S D}=.41$, Objective $_{M}=8.54 \%$, Objective $\left.S D_{S}=.28\right)$. Overall, participants were not very likely to continue listening to the second halves of the programs. It is possible that participants opted to avoid continuing in order to exit the study sooner, regardless of condition.

In our second pre-registered analysis, we conducted a generalized linear mixed model examining the influence of emotion condition (dummy coded as compassion $=1$ and objective $=$ 0 ) on choices to continue. The nature of the design was such that there were only two time points. We used SPSS GENLINMIXED to run a model with a random intercept for subject, and treating time as a repeated measure. In order for the model to converge, we had to set the covariance for the repeated measures of time to be identity. We only estimated a fixed effect of emotion condition. Contrary to our prediction, there was not a difference in choosing to continue between the compassion and objective conditions, $\mathrm{B}=-.43, t=-1.03, p=.304$, odds ratio $=.65$, $95 \%$ CI odds ratio $[.29,1.47]$.

Cognitive costs. In our third pre-registered analysis, we conducted repeated measures ANOVAs to examine whether participants rated the compassion listening instructions to be more effortful, aversive, and less efficacious than the objective detachment listening instructions. 
Contrary to expectations, participants rated compassion as less effortful and less aversive than objective detachment, with no differences emerging for efficacy (see Table 11). Additionally, participants rated compassion as more rewarding and valuable than objective detachment.

Overall, the cost-benefit assessment of compassion (relative to objective detachment) appeared to change in this study, with fewer perceived cognitive costs and increased felt reward and value, though the effect sizes for these differences were somewhat small.

Table 11. Cost and reward ratings in Study 8.

\begin{tabular}{ccccccc}
\hline & Compassion & Objectivity & $M_{\text {diff }}$ & & & Hedges' \\
Measure & $M(S D)$ & $M(S D)$ & {$[95 \% \mathrm{CI}]$} & $F$ & $p$ & $g$ \\
\hline Effort & $2.17(1.16)$ & $2.40(1.18)$ & {$[-0.41,-0.04]$} & 6.04 & .015 & -0.19 \\
Aversion & $1.69(1.07)$ & $1.94(1.20)$ & {$[-0.41,-0.10]$} & 10.42 & .001 & -0.22 \\
Efficacy & $4.12(1.06)$ & $3.97(1.05)$ & {$[-0.05,0.34]$} & 2.15 & .145 & 0.14 \\
Reward & $2.81(1.16)$ & $2.58(1.19)$ & {$[0.09,0.38]$} & 9.67 & .002 & 0.20 \\
Value & $3.19(1.21)$ & $2.93(1.29)$ & {$[0.09,0.42]$} & 9.68 & .002 & 0.20 \\
\hline
\end{tabular}

In our fourth pre-registered analysis, we examined correlations of cognitive costs with choosing to continue listening to the radio broadcast program within each of the two listening instruction conditions. Within the compassion condition, participants were less likely to choose to continue listening to the second half of the program when they perceived the instructions to be more effortful $(r=-.16, p=.035)$, but there were no associations with aversion $(r=-.04, p=$ $.622)$ or efficacy $(r=.13, p=.081)$. Within the objective condition, participants were less likely to choose to continue listening to the second half of the program when they perceived the instructions to be more aversive $(r=-.21, p=.005)$, but there were no associations with effort ( $r$ $=-.04, p=.609)$ or efficacy $(r=.14, p=.065)$. Thus, results provided mixed evidence for the hypothesis that cognitive costs would associate with choice to continue. Additional analysis on the reward and value items revealed that within the compassion condition, participants chose to keep listening when they perceived compassion to be more rewarding $(r=.20, p=.008)$, more 
valuable $(r=.25, p=.001)$, but such associations did not emerge in the objective condition for perceived reward $(r=-.00, p=.988)$ or felt value $(r=.04, p=.621)$.

To complement the pre-registered analysis, we conducted an exploratory analysis testing the associations of difference scores for the cost/reward measures (e.g., effort for compassion minus effort for objective detachment) with the difference in choosing to continue between the compassion and objective tasks. This analysis parallels the approach with the empathy selection task in Studies 1-7, in which deck selection was relative between two options and then tested for associations with deck differences in costs. Here, preference to continue with compassion (vs. objectivity) associated negatively with perceptions of compassion (vs. objectivity) as effortful ( $r$ $=-.34, p<.001)$ and aversive $(r=-.22, p=.003)$, and positively with perceptions of compassion (vs. objectivity) as rewarding ( $r=.21, p=.006)$ and valuable $(r=.19, p=.013)$, with no effect for efficacy $(r=.14, p=.066)$.

State affect and concern ratings. In our fifth pre-registered analysis, we conducted a generalized linear mixed model to compare state concern ratings after compassion and objective detachment listening instructions (all means presented below are estimated marginal means). Participants reported more concern for the person in the radio broadcast program when in the compassion condition $(M=7.05, S E=0.14)$ compared to the objective condition $(M=6.36, S E$ $=0.14), \mathrm{B}=.69, S E=0.15, t(171)=4.46, p<.001,95 \% \mathrm{CI}[.38, .99]$, supporting our hypothesis. Additionally, we used similar models to explore whether valence and arousal ratings differed across the listening instructions. Participants reported higher arousal after the compassion task $(M=3.85, S E=0.17)$ compared to the objective task $(M=3.53, S E=0.17), \mathrm{B}$ $=0.31, S E=0.14, t(171)=2.21, p=.028,95 \% \mathrm{CI}[.03, .59]$. There were no differences in 
valence between the compassion condition $(M=4.46, S E=0.13)$ compared to the objective condition $(M=4.48, S E=0.13), \mathrm{B}=-.02, S E=0.12, t(171)=-0.19, p=.849,95 \%$ CI $[-.26, .22]$.

In summary, the current study used a more immersive audio presentation of suffering and a different paradigm to examine whether and why people avoid compassion for others. Contrary to predictions, participants did not prefer to escape compassion more than objective detachment. Although the method in Study 8 moved away from relative preferences between two choice options, it may be that comparisons between the two tasks shaped people's responses. Importantly, participants still opted to avoid further exposure to compassion, escaping the situation that was calling for them to continue generating compassion, even though escape preferences were not different for objective detachment. Furthermore, the highly immersive nature of the stimuli in these studies - with audio narration, substantive context, and only a single trial per condition - may have limited the ability to detect decreasing unwillingness to exert effort to generate compassion for these individuals.

Additionally, across task conditions, compassion in Study 8 was seen as cognitively easier than the compassion task in previous studies (see Table 4 for Studies 1-7, and Table 11 for Study 8). It may be that the immersive, contextually enriched compassion stimulus made the task of cultivating compassion easier compared to previous studies. Additionally, cultivating compassion once may be easier than cultivating compassion over a large number of trials. Compassion choice over a larger number of trials (as in Studies 1-7) may allow a purer test of behavioral preferences to choose or avoid compassion, building on previous free-choice approaches in the study of effort avoidance (Kool et al., 2010) and emotion regulation choice (Sheppes et al., 2014). Choice on any single trial may be determined by a number of factors, and as such, it may be that cognitive costs of compassion, and resulting compassion avoidance, are 
more evident in situations where participants have to sustain compassion over time. Here, we note that in the condition in which compassion came first, participants rated compassion as involving less cognitive effort, and as more rewarding and valuable, which may suggest that the more immersive charitable pleas with more context around the victim's suffering may have provided some motivation to continue cultivating compassion. The one-shot choice, meant to capture ecological realism, may have limited our ability to assess whether motivation to exert effort to generate compassion actually wanes over time.

Nevertheless, we still observed that participants opted to avoid compassion in favor of escaping the charitable plea, which mimics the choice to avoid compassion across Studies 1-7 for complete strangers (though, avoidance was fairly consistent across objective detachment and compassion conditions without taking task order into account). This may suggest that introducing an escape route may have increased the perceived opportunity costs of further engaging with compassion or objective detachment in their respective conditions (Kurzban et al., 2013). Lastly, cognitive costs such as effort and aversion (but not efficacy) associated with subsequent escape of compassion.

\section{General Discussion}

Compassion and empathy are often discussed as cornerstones of prosociality, with much debate and difference of opinion as to their appropriate relations to each other. Whereas some scholars have noted that these psychological experiences share affective, cognitive, and motivational components (Decety \& Cowell, 2014; Zaki \& Oschner, 2012), others separate their components in order to examine whether compassion may be a more sustainable solution in motivating prosocial behavior (Klimecki et al., 2013, 2014). For some, compassion is thought to entail fewer costs, motivating ethical conclusions that compassion should guide prosociality over 
empathy (e.g., Bloom, 2017). Yet not all agree that compassion is necessarily easier to generate and sustain (for discussion, see Goetz et al., 2010). Without measuring whether people want to feel compassion when given the choice and examining how such preferences relate to felt cognitive demands, such claims about compassion may be premature.

Our results challenge overly positive views of compassion: When given the choice between compassion and an alternative course of action—such as objective detachment and empathy — people strongly preferred to avoid compassion for strangers. Though compassion has been proposed by some (though not all) as easy and pleasant (e.g., Bloom, 2017; Singer \& Klimecki, 2014), participants in the current studies viewed compassion for strangers as hard work and avoided it. We did reveal two important boundary conditions: social proximity and contextual immersion. In Studies 6 and 7, participants avoided compassion for strangers but not close others. Furthermore, in Study 8, participants chose whether to continue generating compassion for a single, contextually enriched target. Although participants did opt to avoid compassion in the final study, this preference did not differ from the choice to avoid objective detachment. Furthermore, perceiving compassion as more cognitively taxing associated with reduced compassion choice. Appreciating how cognitive costs interact with decision-makers' goals may help scientists, ethicists, and philanthropists better understand when and why people care for others.

\section{Motivated Regulation of Compassion}

The current studies highlight the utility of examining compassion regulation and choice, adding a new methodological approach to the study of this emotion. Whereas much previous work examines compassion using trait self-report measures, experimental inductions, or state compassion measures, these methods leave open the process of how compassion is actively and 
spontaneously managed. Rather than directing people to feel compassion, we let people choose to feel compassion, allowing us to document choice preferences that associated with felt cognitive costs. We recommend such approaches using situation selection be adopted to examine how people manage compassion in everyday life-by choosing to approach or avoid contexts that elicit requests for compassionate concern. Experimental manipulations do not provide people with the choice of engaging in these feelings; and given that people may often be motivated to avoid compassion, it is important to model this as a free choice in order to understand the prevalence and causes of compassion. Self-report measures of trait or state compassion can be useful in diagnosing either retrospective or current experiences of compassion but speak less to how people might systematically shape those feelings using emotion regulation strategies. By measuring the regulation of compassion, the current work provides a new method to understand this potentially important aspect of compassion. More specifically, the empathy selection task allows testing of the propensity or willingness to choose compassion (Keysers \& Gazzola, 2014), and such focus on motivated choices is uncommon in research on compassion (for another example, see Miralles et al., 2019).

We additionally uncovered an important boundary condition for compassion regulation: in Studies 6 and 7, participants were less likely to avoid compassion for close others. These studies validated that people generated stronger feelings of compassion when choosing the compassion deck. Furthermore, compassion for close (vs. distant) others was rated as less costly and more valuable, and these differences in costs and rewards of compassion associated with choosing compassion more for close others. These results build upon prior work showing parochial bias in empathy (e.g., Bruneau et al., 2017) by revealing processes by which parochialism in compassion can be created - namely, through selecting out of situations calling 
for compassion for distant (vs. close) others. It may be that parochial bias in compassion reflects differences in responsiveness to the suffering of close versus distant others. But it could equally reflect preferences for whom people want to feel compassion toward, and people may prefer choosing compassion for those who seem to provide the most relationship benefits (DeSteno, 2015). Not only do the current results help uncover how compassion regulation might underpin parochialism, they also link parochial compassion regulation to one relevant motivational factor: cognitive work. Prior work has linked anticipated emotional exhaustion to dehumanization of outgroups (Cameron et al., 2016), but did not systematically examine processes of emotion regulation or cognitive effort as a motivational factor.

\section{Compassion as Cognitively Taxing}

Considering the cognitive costs of compassion can generate new questions to expand the study of prosociality. Some conceptualizations of compassion suggest that efficacy is an important component (Goetz et al., 2010). To the extent that compassion for strangers is felt as taxing and avoided for that reason, future work could examine interventions to change these costs and in turn, increase compassion choice. One approach would be to manipulate cognitive costs such as efficacy. In Supplemental Studies S1-S3, we experimentally manipulated perceived efficacy at compassion, but did not find consistent effects on compassion choice. The current work suggests that contextual variation is another approach, as social proximity reduced some cognitive costs of compassion and offset them with perceived value. This social proximity effect may reflect intergroup empathy deficits more generally (Cikara et al., 2014), and it is possible that compassion for strangers could be cultivated and made easier with practice (Ekman, 2014; Klimecki et al., 2014; for discussion, see Roeser et al., 2018). Furthermore, more immersive and 
contextually enriched contexts (Study 8) appear to make compassion easier, suggesting another way to provide external support for compassionate choices.

The current results leave open the question of whether compassion choice is driven by perceived or actual cognitive work. Prior studies suggest that expectations of cognitive effort can play a role in how people make strategic task choices (Dunn et al., 2019), and other work suggests that perceptions of autonomy for task engagement predicts opportunity costs and subsequent felt effort (Rom et al., 2020). We think that both could be plausible in the current studies. In Studies 1-7, ratings of cognitive effort, aversion, and efficacy were made after the empathy selection task. These may capture retrospective judgments about experienced cognitive costs of compassion and the contrast deck during the empathy selection task. This correlational data cannot reveal whether cognitive costs shaped compassion choices or were a post-hoc justification of choices to avoid compassion.

Nevertheless, we note the meta-analytic decline in compassion choice over time, which might suggest strategic incorporation of felt work to motivate further avoidance during the task. Additionally, the declines in state compassionate concern over time in Studies 6 and 7 might suggest a role both for anticipated and experienced effort of compassion as the task proceeded. Furthermore, in Study 8, we assessed cognitive costs of compassion and objective detachment in between the first and second exposure to the audio stimuli, allowing for prospective prediction of choice to continue (for each of the compassion and objectivity conditions, respectively) from these ratings. We found that many of the cognitive work ratings (effort and aversion, though here not efficacy) associated with decisions to escape further exposure to the audio stimuli, suggesting a role both for the experience of cognitive work (based on prior exposure to first half) and expectations of future work (about what the second half would be like). 


\section{Reconsidering Compassion}

As noted in the Introduction, there is debate about the relationship between compassion and empathy, with some suggesting that compassion is a facet of empathy whereas others suggesting these are distinct psychological states. One question that might arise from this debate is whether people can sufficiently distinguish between compassion and empathy in their own experience. Do people perceive compassion as different from empathy, and does individual variability in whether they do so shape whether they choose to engage with or avoid compassion? We suggest this is an interesting question for future research. Previous work has shown that guiding participants to cultivate compassion or empathic resonance can lead to different subjective effects (Klimecki et al., 2014), and self-reported trait measures of these states can associate with different outcomes (Jordan et al., 2016; Mayukha et al., 2020). Presently, the broader debate which inspired this work directly contrasts the subjective experience and behavioral effects of empathy and compassion. Although empathy and compassion may often work together, the question about the relative merits of each lends itself to a method which pits them against each other and allows people to make a free choice between them and also evaluate their cognitive difficulty. We note that this sort of approach has precedent in cognitive neuroscience (e.g., Kool et al., 2010; Westbrook et al., 2013), which uses free choice to directly compare response options that have different associated levels of value.

Empirically, we note in Study 6, which contrasted compassion and empathy for close and distant others, when participants selected compassion (over empathy), they displayed higher trial-level concern ratings. This result suggests that participants may be disentangling these responses in reporting how they feel. Moreover, if they were unable to fully distinguish the two, it would be unlikely for them to show a robust preference for one or the other, and yet 
participants preferred to avoid compassion in favor of empathy. We acknowledge that in naturalistic situations in which empathy and compassion might be co-activated (Depow et al., 2021), the relative costs of each may not always be so clear cut, and more work should be done to examine when and how people are able to discern differences between compassion and empathy.

Not all perspectives treat compassion as an emotion, with some contemplative traditions considering compassion to be more akin to an attitude or orientation (Gilbert, 2018) that encompasses emotion, motivation, and behavior. The current work focuses primarily on compassion as an emotion, and future work should present diversified approaches to compassion as a target of emotion regulation. For example, the empathy selection task could be adapted such that participants are encouraged to express a wish that someone be free from suffering and its causes, a behavioral focus which is a part of many compassion meditation traditions (Jazaieri et al., 2013; Roeser et al., 2018). The task instructions in Studies 1, 3, and 5 did emphasize both compassion generation and also writing about how to engage in caring behavior for the person, but more work is needed to fully encompass the range of ways in which compassion has been conceptualized across varying traditions of research and practices of compassion.

\section{Measuring Compassion Choice}

These studies build upon previous work validating the empathy selection task by extending the task's scope to compassion and by identifying social and motivational moderators of choice in the task (see also Ferguson et al., 2020). Importantly, the boundary condition of close vs. distant others in Studies 6 and 7 reveal the utility of the approach: choice effects varied as a function of who the target of compassion was, and these associated with corresponding changes in perceived cognitive costs of compassion, providing a window onto emotion 
regulation processes as well as their motivational precursors. The complementary approach in Study 8 , which used a more ecologically realistic and immersive escape paradigm, also provides a platform for further research to explore how contextual richness might matter for compassion avoidance effects.

From a motivated empathy perspective (Cameron, 2018; Keysers \& Gazzola, 2014; Zaki, 2014), and from work using the empathy selection task (Cameron et al., 2019), it is important to consider opportunity costs: how the potential alternative course of action may matter for perceived effort and goal selection (e.g., Rom et al., 2020). We modeled the objective deck from previous research on the empathy-altruism hypothesis (for review, see Batson, 2011). Additionally, the objective deck was used in prior work with the empathy selection task (Cameron et al., 2019) in which participants were provided with the choice to feel empathy or remain objectively detached from social targets. Objective detachment has the potential to be demanding, particularly in response to intense emotional stimuli; for example, choices to use the related emotion regulation strategy of reappraisal seem sensitive to emotional intensity and cognitive demands (Milyavsky et al., 2018; Sheppes et al., 2014). Moreover, recent work about the nature of the contrast in empathy inductions (e.g., McAuliffe et al., 2018, 2020) finds that the objective contrast condition in many empathy-altruism studies drives empathic concern downward, suggesting that it is important to attend to the contrast conditions in empathy or compassion studies. The opportunity costs of choosing to feel compassion may shift when lesser effortful pathways are present; if compassion is contrasted against something more effortful, for example, then presumably people would favor compassion. Such a result was observed in one condition of Study 8; when participants saw the compassion trial before the objective trial, they rated compassion as comparatively easier than objectivity and also were less likely to escape it. 
Future work could usefully compare compassion against anger or other negative-valence comparison decks, to understand whether people might choose compassion differently depending on the contrast in question. We predict that any such differences would associate with felt differences in the cognitive costs of each deck. For example, if directing anger at perpetrators was felt as more cognitively demanding than generating compassion for victims, this might lead people to prefer compassion to anger, and presumably they would rate the effort costs differently. On the other hand, if anger felt easier to cultivate than compassion, people might choose to up-regulate anger for perpetrators instead of compassion for victims.

One related limitation in Studies 1-7 is that the explicit labels applied to the decks ("CARE", "FEEL") may have captured particular semantic associations and created a distinction between compassion and feelings more generally. We selected the terms "CARE" and "FEEL" as two seemingly different terms to broadly connote the types of tasks that would be required for each deck, without explicitly mentioning the terms "compassion" and "empathy" in order to avoid any pre-existing biases that people might have for those terms. Furthermore, prior work with the empathy selection task finds fairly similar effects across types of deck label (Cameron et al., 2019). We also suggest that the trial-level instructions are very important for understanding participants' decisions of which deck to avoid. For instance, in Studies 3-4, our trial-level instructions explicitly encouraged either compassion or experience sharing in more substantial detail, and even with very different instructions guiding these processes, similar preferences for empathy over compassion emerged across the two studies. We also note that even though task operationalizations changed across the eight studies presented here, compassion avoidance effects emerged in all studies.

\section{Limitations}


One limitation of the primary method used across Studies 1-7 - the empathy selection task - is that it presents minimal context and may have less external validity and applicability to everyday contexts of compassion. There are real-world analogues of situation selection involving compassion, such as deciding whether to choose to read a petition about a cause, however we recognize this may be an important limitation. It may also be that the number of choices presented to participants in the empathy selection task may deviate from more typical single-shot encounters in everyday life, potentially increasing felt cognitive burden (though as noted in the introduction, the literature on compassion fatigue suggests that repeated compassion exposure may have important real-world analogues; Figley, 2002).

Even though this variation on the empathy selection task may lack some degree of external validity, this concern may still be tolerable as long as the method can provide an internally valid test of the questions of interest (i.e., by providing a structured examination of how people actively choose to engage with compassion or not; see Mook, 1983, and Aronson et al., 1998, for discussion of tradeoffs between external validity and internal validity). Although there have been many valuable insights about the role of context in empathy studies (e.g., FeldmanHall et al., 2012), we suggest that there can sometimes be advantages of a "context-free" approach so long as it provides a useful and valid test of psychological processes. The repeated measurement of choices builds from previous work which uses repeated trials to establish reliable estimates of behavioral preferences (e.g., Kool et al., 2010; Sheppes et al., 2014). On the other hand, a single choice may be determined by a number of factors (e.g., opportunity costs; Rom et al., 2020), which may make felt effort as the reason for avoidance harder to isolate. Similarly, for some psychological phenomena, motivational factors (such as effort) may only reveal their role through sustained engagement. For instance, it may be that people have to 
cultivate compassion repeatedly to feel the cognitive effort involved. Interestingly, even in the single-trial immersive paradigm in Study 8, prospective ratings of cognitive effort predicted subsequent compassion avoidance.

Although the empathy selection task approach in Studies 1-5 did not specify why the depicted targets were suffering or provide identifying information about the targets, these details were added in Studies 6 and 7 when participants imagined close and distant others undergoing negative events. Study 8 used a more contextually immersive paradigm with only a single trial per condition, with pairs of longer audio recordings used in prior work and opted whether to proceed to the second half of each recording (once under a compassion instruction, once under an objective instruction). Even in this single-shot approach, participants still opted to avoid compassion, although they did not avoid compassion more than they did for objective detachment. One notable finding from the single-shot approach in Study 8 was that compassion was rated as cognitively easier in this study compared to previous studies, which may explain why there were not differential preferences to avoid compassion and objective detachment. Future work should continue to examine how adding detailed contextual information and reducing the number of compassion targets might shape preferences to choose compassion.

Another limitation of the current work is that participants did not have the opportunity to engage in prosocial behavior, to act on their compassion in a more concrete way. Given that one function of compassion is to care for others (DeSteno, 2015; Goetz et al., 2010), it is possible this created frustration in participants that they could not act on compassion, leading them to avoid it compared to empathy and objective detachment. The present studies attempted to remove expected prosocial behavior as a material cost of compassion, in order to isolate the cognitive effort costs that might be associated with compassion (similar to the design logic in 
Cameron et al., 2019). It is possible that giving people the sense that their compassion will have a prosocial impact might make it seem more useful and relevant (Tamir, 2009), but it could on the other hand act as an additional deterrent above and beyond cognitive costs (Cameron \& Payne, 2011). In Studies 7 and 8, compassion was rated as more rewarding and valuable than objective detachment, and associated positively with choices to feel compassion, suggesting that even in the face of some cognitive effort costs people might still find value in compassion and choose it. More work needs to be done to systematically understand the role of effort, utility, and value when considering how people understand the cognitive work of compassion.

Although on average people prefer to avoid effort, there are exceptions, and in these studies, there was variability in compassion choice even for strangers. People who strongly value having a compassionate identity may overlook compassion's effort, or construe such effort as more valuable, motivating them to choose compassion (Inzlicht et al., 2018). Thus, we examined whether trait compassion associated with compassion choice across studies. In Studies 1-7, which assessed with compassion choice using the empathy selection task, there was a small relationship between the Interpersonal Reactivity Index Empathy Concern sub-scale (Davis, 1983) and compassion choice, $r=.11, Z=2.02, p=.043$ (using random-effects meta-analysis, Borenstein et al., 2009). In Study 8, which assessed compassion choice using a more immersive listening/escape paradigm, there was also a small effect, $r=.23, p=.002$. Given these small effects, more work is needed to understand the relationship between internalized values, costs and rewards, and compassionate choices.

\section{Conclusion}

We uncovered an underappreciated cost of compassion—participants viewed compassion as cognitively taxing, and possibly for this reason, chose to avoid it. When directed toward 
strangers, compassion did not appear to be an easier alternative to empathy and was rated as

more challenging. This effect changed when directed toward close others, where compassion was chosen more frequently and perceived as easier. With a more contextually enriched single target, participants still opted to avoid compassion, though not to a greater extent than objective detachment. These studies are the first to link compassion choice variation across relationships to cognitive costs and suggest novel directions for studying compassion. If compassion for close others is felt as easier and more rewarding, then by encouraging people to see similarity between strangers and those they love, compassion choice might be increased. Thus, compassion for others only emerges when you want to put in the effort to care.

\section{Context of the Research}

This research developed with the broader psychological and ethical debates about the utility of moral processes like empathy and compassion for sustaining prosocial behavior (e.g., Bloom, 2016; Singer \& Klimecki, 2014)—with claims that empathy is felt as fatiguing and liable to burnout, but compassion is felt as rewarding and cost-free (Bloom, 2017; Klimecki et al., $2013 ; 2014)$. The current work examines whether and why people choose to avoid compassion (compared to empathy and objective detachment), building upon cognitive methodologies used to examine effort avoidance (Kool et al., 2010) and empathy avoidance (Cameron et al., 2019). These studies continue each authors' distinct research programs, including Scheffer's work on compassion and morality (Scheffer et al., 2020), Cameron's studies of motivated empathy (Cameron et al., 2019), and Inzlicht's research on effort (Lin et al., 2020). Compassion, at least for strangers and in some contexts of suffering, appears to have cognitive effort costs that associate with people choosing to avoid it. The current work contributes to the broader debate about whether compassion is a preferable process for motivating and guiding prosocial decisions 
in everyday life (Bloom, 2017): compassion is not always felt as pleasant and rewarding for strangers, which largely represents the targets of philanthropic appeals. Instead, compassion and caring can sometimes be cognitively costly, suggesting a need to study when and why people choose to approach or avoid it. 


\section{Acknowledgements}

We thank Eliana Hadjiandreou and Stephanie McKee for assistance with programming, data collection, data compilation, and helpful comments on this paper. We also thank Marco Ciappetta, Jessica Manero, and Cassie Sieradzky for assistance with data collection. Lastly, we thank Jose Soto, Sinhae Cho, and Robert Roeser for helpful comments on this paper. The authors acknowledge funding support by the Rock Ethics Institute at the Pennsylvania State University to JAS, by NSF grant \#1660707 and John Templeton Foundation Grant \#61150 to CDC, and by grant 435-2019-0144 from the Social Sciences and Humanities Research Council of Canada and grant RGPIN-2019-05280 from the Natural Sciences and Engineering Research Council of Canada to MI. Talks for this work were presented at the Society for Affective Science and the Society for Personality and Social Psychology by CDC, and posters for this work were presented at the Society for Personality and Social Psychology by JAS. Further, talks including this data were presented at Northeastern University, DePaul University, Lehigh University, and Stanford University by CDC, with the latter two involving small paid honoraria. 


\section{References}

Ang, Y. S., Lockwood, P., Apps, M. A., Muhammed, K., \& Husain, M. (2017). Distinct subtypes of apathy revealed by the apathy motivation index. PLoS One, 12(1), e0169938. https://doi.org/10.1371/journal.pone.0169938

Aronson, E., Wilson, T. D., \& Brewer, M. B. (1998). Experimentation in social psychology. In D. T. Gilbert, S. T. Fiske, \& G. Lindzey (Eds.), The handbook of social psychology (4th ed., Vol. 1, pp. 99-142). Boston: McGraw-Hill.

Batson, C.D. (2011). Altruism in Humans. New York, NY: Oxford University Press.

Batson, C. D. (2009). These things called empathy: Eight related but distinct phenomena. In J. Decety \& W. Ickes (Eds.), Social neuroscience. The social neuroscience of empathy (p. 3-15). MIT Press. https://doi.org/10.7551/mitpress/9780262012973.003.0002

Batson, C. D., \& Ahmad, N. Y. (2009). Using empathy to improve intergroup attitudes and relations. Social Issues and Policy Review, 3(1), 141-177. https://doi.org/10.1111/j.17512409.2009.01013.x

Batson, C. D., O'Quin, K., Fultz, J., Vanderplas, M., \& Isen, A. M. (1983). Influence of selfreported distress and empathy on egoistic versus altruistic motivation to help. Journal of Personality and Social Psychology, 45(3), 706-718. https://doi.org/10.1037/00223514.45.3.706

Blaffer Hrdy, S. (2011). Mothers and Others: The Evolutionary Origins of Mutual Understanding. Belknap Press.

Bloom, P. (2017). Empathy and its discontents. Trends in Cognitive Sciences, 21(1), 24-31. doi: 10.1016/j.tics.2016.11.004.

Borenstein, M., Hedges, L.V., Higgins, J.P.T., \& Rothstein, H.R. (2009). When does it make 
sense to perform a meta-analysis?. In M. Borenstein, Hedges, L.V., Higgins, J.P.T., \& Rothstein, H.R. (Eds.) Introduction to meta-analysis (pp. 357-364). New York, NY: John Wiley \& Sons Ltd.

Borenstein, M., Hedges, L.V., Higgins, J.P.T., \& Rothstein, H.R. (2013). Comprehensive metaanalysis (Version 3). Biostat, Englewood, NJ.

Bradley, M.M., \& Lang, P.J. (1994). Measuring emotion: The Self-Assessment Manikin and the semantic differential. Journal of Behavior Therapy and Experimental Psychiatry, 25(1), 49-59. https://doi.org/10.1016/0005-7916(94)90063-9

Bruneau, E. G., Cikara, M., \& Saxe, R. (2015). Minding the gap: Narrative descriptions about mental states attenuate parochial empathy. PloS One, 10(10), e0140838. https://doi.org/10.1371/journal.pone.0140838

Bruneau, E. G., Cikara, M., \& Saxe, R. (2017). Parochial empathy predicts reduced altruism and the endorsement of passive harm. Social Psychological and Personality Science, 8(8), 934-942. https://doi.org/10.1177/1948550617693064

Cameron, C. D. (2018). Motivating empathy: Three methodological recommendations for mapping empathy. Social and Personality Psychology Compass, 12(11), e12418. https://doi.org/10.1111/spc3.12418

Cameron, C. D., Hutcherson, C. A., Ferguson, A. M., Scheffer, J. A., Hadjiandreou, E., \& Inzlicht, M. (2019). Empathy is hard work: People choose to avoid empathy because of its cognitive costs. Journal of Experimental Psychology: General, 148(6), 962-976. https://doi.org/10.1037/xge0000595 
Cameron, C. D., \& Inzlicht, M. (2020). Empathy choice in physicians and nonphysicians. British Journal of Social Psychology, 59(3), 715-732. https://doi.org/10.1111/bjso.12342

Cameron, C. D., \& Payne, B. K. (2011). Escaping affect: How motivated emotion regulation creates insensitivity to mass suffering. Journal of Personality and Social Psychology, 100(1), 1-15. doi: 10.1037/a0021643.

Cameron, C. D., Harris, L. T., \& Payne, B. K. (2016). The emotional cost of humanity: Anticipated exhaustion motivates dehumanization of stigmatized targets. Social Psychological and Personality Science, 7(2), 105-112. https://doi.org/10.1177/1948550615604453

Cikara, M., Bruneau, E. G., \& Saxe, R. R. (2011). Us and them: Intergroup failures of empathy. Current Directions in Psychological Science, 20(3), 149-153. https://doi.org/10.1177/0963721411408713

Cikara, M., Bruneau, E., Van Bavel, J. J., \& Saxe, R. (2014). Their pain gives us pleasure: How intergroup dynamics shape empathic failures and counter-empathic responses. Journal of Experimental Social Psychology, 55, 110-125. doi: 10.1016/j.jesp.2014.06.007

Condon, P., \& Feldman Barrett, L. (2013). Conceptualizing and experiencing compassion. Emotion, 13(5), 817-821. https://doi.org/10.1037/a0033747

Davis, M. H. (1983). Measuring individual differences in empathy: Evidence for a multidimensional approach. Journal of Personality and Social Psychology, 44(1), 113126. https://doi.org/10.1037/0022-3514.44.1.113

Decety, J., Bartal, I. B. A., Uzefovsky, F., \& Knafo-Noam, A. (2016). Empathy as a driver of 
prosocial behavior: Highly conserved neurobehavioral mechanisms across species. Phil. Trans. R. Soc. B, 371(1686), 20150077. doi: 10.1098/rstb.2015.0077

Decety, J., \& Cowell, J. M. (2014). The complex relation between morality and empathy. Trends in Cognitive Sciences, 18(7), 337-339. doi: 10.1016/j.tics.2014.04.008

Depow, G. J., Francis, Z. L., \& Inzlicht, M. (in press). The experience of empathy in everyday life. Psychological Science. Preprint retrieved from https://psyarxiv.com/hjuab

DeSteno, D. (2015). Compassion and altruism: How our minds determine who is worthy of help. Current Opinion in Behavioral Sciences, 3, 80-83. https://doi.org/10.1016/j.cobeha.2015.02.002

Dunn, T. L., Inzlicht, M., \& Risko, E. F. (2019). Anticipating cognitive effort: Roles of perceived error-likelihood and time demands. Psychological Research, 83(5), 1033-1056. doi: $10.1007 / \mathrm{s} 00426-017-0943-\mathrm{x}$

Dziobek, I., Rogers, K., Fleck, S., Bahnemann, M., Heekeren, H. R., Wolf, O. T., \& Convit, A. (2008). Dissociation of cognitive and emotional empathy in adults with Asperger syndrome using the Multifaceted Empathy Test (MET). Journal of Autism and Developmental Disorders, 38(3), 464-473. doi: 10.1007/s10803-007-0486-x

Eisenberg, N., \& Eggum, N. D. (2009). Empathic responding: Sympathy and personal distress. In: J. Decety \& W. Ickes (Eds.), The Social Neuroscience of Empathy. Cambridge, MA: MIT Press, 71-83. https://doi.org/10.7551/mitpress/9780262012973.003.0007

Eisenberg, N., Fabes, R. A., Murphy, B., Karbon, M., Smith, M., \& Maszk, P. (1996). 
The relations of children's dispositional empathy-related responding to their emotionality, regulation, and social functioning. Developmental Psychology, 32(2), 195-209. https://doi.org/10.1037/0012-1649.32.2.195

Eisenberg, N., Wentzel, M., \& Harris, J. D. (1998). The role of emotionality and regulation in empathy-related responding. School Psychology Review, 27(4), 506-521. DOI: $10.1080 / 02796015.1998 .12085934$

Ekman, P. (2014). Moving Toward Global Compassion. San Francisco, CA: Ekman Group. Engen, H. G., \& Singer, T. (2015). Compassion-based emotion regulation up-regulates experienced positive affect and associated neural networks. Social Cognitive and Affective Neuroscience, 10(9), 1291-1301. doi: 10.1093/scan/nsv008

Faul, F., Erdfelder, E., Buchner, A., \& Lang, A.-G. (2009). Statistical power analyses using G*Power 3.1: Tests for correlation and regression analyses. Behavior Research Methods, 41, 1149-1160. https://doi.org/10.3758/BRM.41.4.1149

FeldmanHall, O., Mobbs, D., Evans, D., Hiscox, L., Navrady, L., \& Dalgleish, T. (2012). What we say and what we do: the relationship between real and hypothetical moral choices. Cognition, 123(3), 434-441. doi: 10.1016/j.cognition.2012.02.001

Ferguson, A. M., Cameron, C. D., \& Inzlicht, M. (2020). Motivational effects on empathic choices. Journal of Experimental Social Psychology, 90, 104010. https://doi.org/10.1016/j.jesp.2020.104010

Figley, C.R. (2002). Compassion fatigue: Psychotherapists' chronic lack of self care. Journal of Clinical Psychology, 58(11), 1433-1441. https://doi.org/10.1002/jclp.10090

Fiske, S.T., \& Taylor, S.E. (1984). Social cognition ( $1^{\text {st }}$ ed.). Reading, MA: Addison-Wesley. 
Gilbert, P. (2018). Explorations into the nature and function of compassion. Current Opinion in Psychology, 28, 108-114. https://doi.org/10.1016/j.copsyc.2018.12.002

Goetz, J. L., Keltner, D., \& Simon-Thomas, E. (2010). Compassion: An evolutionary analysis and empirical review. Psychological Bulletin, 136(3), 351-374. https://doi.org/10.1037/a0018807

Gross, J. J. (2001). Emotion regulation in adulthood: Timing is everything. Current Directions in Psychological Science, 10(6), 214-219. https://doi.org/10.1111/1467-8721.00152

Gross, J. J., \& Thompson, R. A. (2007). Emotion regulation: Conceptual foundations. In J. J. Gross (Ed.), Handbook of Emotion Regulation. New York: The Guilford Press.

Gutsell, J. N., \& Inzlicht, M. (2012). Intergroup differences in the sharing of emotive states: Neural evidence of an empathy gap. Social Cognitive and Affective Neuroscience, 7(5), 596-603. doi: 10.1093/scan/nsr035

Hall, J. A., \& Schwartz, R. (2019). Empathy present and future. The Journal of Social Psychology, 159(3), 225-243. https://doi.org/10.1080/00224545.2018.1477442

Hart, S. G., \& Staveland, L. E. (1988). Development of NASA-TLX (Task Load Index): Results of empirical and theoretical research. Advances in Psychology, 52, 139-183. https://doi.org/10.1016/S0166-4115(08)62386-9

Hosking, J. G., Cocker, P. J., \& Winstanley, C. A. (2014). Dissociable contributions of anterior cingulate cortex and basolateral amygdala on a rodent cost/benefit decision-making task of cognitive effort. Neuropsychopharmacology, 39(7), 1558. https://doi.org/10.1038/npp.2014.27 
Hosking, J. G., Cocker, P. J., \& Winstanley, C. A. (2015a). Prefrontal cortical inactivations decrease willingness to expend cognitive effort on a rodent cost/benefit decision-making task. Cerebral Cortex, 26(4), 1529-1538. 10.1093/cercor/bhu321

Hosking, J. G., Floresco, S. B., \& Winstanley, C. A. (2015b). Dopamine antagonism decreases willingness to expend physical, but not cognitive, effort: A comparison of two rodent cost/benefit decision-making tasks. Neuropsychopharmacology, 40(4), 1005-1015. https://doi.org/10.1038/npp.2014.285

Hu, T., Zheng, X., \& Huang, M. (2020). Absence and presence of human interaction: The relationship between loneliness and empathy. Frontiers in Psychology, 11, 768. https://doi.org/10.3389/fpsyg.2020.00768

Hull, C.L. (1943). Principles of Behavior. New York, NY: Appleton-CenturyCrofts.

Inzlicht, M., Shenhav, A., \& Olivola, C.Y. (2018). The effort paradox: Effort is both costly and valued. Trends in Cognitive Sciences, 22(4), 337-349. https://doi.org/10.1016/j.tics.2018.01.007

Jazaieri, H., Jinpa, G. T., McGonigal, K., Rosenberg, E. L., Finkelstein, J., Simon-Thomas, E., ... \& Goldin, P. R. (2013). Enhancing compassion: A randomized controlled trial of a compassion cultivation training program. Journal of Happiness Studies, 14(4), 11131126. https://doi.org/10.1007/s10902-012-9373-z

Jordan, M. R., Amir, D., \& Bloom, P. (2016). Are empathy and concern psychologically distinct?. Emotion, 16(8), 1107-1116. https://doi.org/10.1037/emo0000228

Kanske, P., Böckler, A., Trautwein, F. M., \& Singer, T. (2015). Dissecting the social brain: Introducing the EmpaToM to reveal distinct neural networks and brain-behavior relations 
for empathy and Theory of Mind. NeuroImage, 122, 6-19. doi:

10.1016/j.neuroimage.2015.07.082

Keysers, C., \& Gazzola, V. (2014). Dissociating the ability and propensity for empathy. Trends in Cognitive Sciences, 18(4), 163-166. https://doi.org/10.1016/j.tics.2013.12.011

Klimecki, O. M. (2019). The role of empathy and compassion in conflict resolution. Emotion Review, 11(4), 310-325. https://doi.org/10.1177/1754073919838609

Klimecki, O. M., Leiberg, S., Lamm, C., \& Singer, T. (2013). Functional neural plasticity and associated changes in positive affect after compassion training. Cerebral Cortex, 23(7), 15. doi: $10.1093 /$ cercor/bhs142

Klimecki, O. M., Leiberg, S., Ricard, M., \& Singer, T. (2014). Differential pattern of functional brain plasticity after compassion and empathy training. Social Cognitive and Affective Neuroscience, 9(6), 873-879. doi: 10.1093/scan/nst060

Klimecki, O., \& Singer, T. (2012). Empathic distress fatigue rather than compassion fatigue? Integrating findings from empathy research in psychology and social neuroscience. In B. Oakley, A. Knafo, G. Madhavan, \& D. S. Wilson (Eds.), Pathological altruism (pp. 368383). New York, NY, US: Oxford University Press.

Kool, W., McGuire, J. T., Rosen, Z. B., \& Botvinick, M. M. (2010). Decision making and the avoidance of cognitive demand. Journal of Experimental Psychology: General, 139(4), 665-682. doi: 10.1037/a0020198

Kumashiro, M., \& Sedikides, C. (2005). Taking on board liability-focused information: Close positive relationships as a self-bolstering resource. Psychological Science, 16(9), 732739. https://doi.org/10.1111/j.1467-9280.2005.01603.x 
Kurzban, R., Duckworth, A., Kable, J. W., \& Myers, J. (2013). An opportunity cost model of subjective effort and task performance. Behavioral and Brain Sciences, 36(6), 661-679. doi: 10.1017/S0140525X12003196

Lazarus, R. S. (1991). Cognition and motivation in emotion. American Psychologist, 46(4), 352367. https://doi.org/10.1037/0003-066X.46.4.352

Lin, H., Saunders, B., Friese, M., Evans, N. J., \& Inzlicht, M. (2020). Strong effort manipulations reduce response caution: A preregistered reinvention of the ego-depletion paradigm. Psychological Science, 31(5), 531-547. https://doi.org/10.1177/0956797620904990

Litman, L., Robinson, J., \& Abberbock, T. (2017). TurkPrime. com: A versatile crowdsourcing data acquisition platform for the behavioral sciences. Behavior Research Methods, 49(2), 433-442. https://doi.org/10.3758/s13428-016-0727-z

Lockwood, P., Hamonet, M., Zhang, S., Ratnavel, A., Salmony, F. U., Husain, M., \& Apps, M. A. J. (2017). Prosocial apathy when helping others is too much effort. Nature: Human Behavior, 1(17), 1-10. doi: 10.1038/s41562-017-0131

Marsh, A. A. (2019). The caring continuum: Evolved hormonal and proximal mechanisms explain prosocial and antisocial extremes. Annual Review of Psychology, 70, 347-371. https://doi.org/10.1146/annurev-psych-010418-103010

Mayukha, A., Andrade, I., \& Cone, J. (2020). Opposing contributions of psychologically distinct components of empathy to empathic accuracy. Journal of Experimental Psychology: General. Advance online publication. https://doi.org/10.1037/xge0000768 
McAuliffe, W. H., Forster, D. E., Philippe, J., \& McCullough, M. E. (2018). Digital altruists: Resolving key questions about the empathy-altruism hypothesis in an Internet sample. Emotion, 18(4), 493-506. doi: 10.1037/emo0000375

McAuliffe, W. H., Carter, E. C., Berhane, J., Snihur, A. C., \& McCullough, M. E. (2020). Is empathy the default response to suffering? A meta-analytic evaluation of perspective taking's effect on empathic concern. Personality and Social Psychology Review, 24(2), 141-162. https://doi.org/10.1177/1088868319887599

Milyavsky, M., Webber, D., Fernandez, J. R., Kruglanski, A. W., Goldenberg, A., Suri, G., \& Gross, J. J. (2019). To reappraise or not to reappraise? Emotion regulation choice and cognitive energetics. Emotion, 19(6), 964-981. https://doi.org/10.1037/emo0000498

Miralles, A., Raymond, M. \& Lecointre, G. Empathy and compassion toward other species decrease with evolutionary divergence time. Scientific Reports, 9, 19555 (2019). https://doi.org/10.1038/s41598-019-56006-9.

Mook, D. G. (1983). In defense of external invalidity. American Psychologist, 38(4), 379-387. https://doi.org/10.1037/0003-066X.38.4.379

Oveis, C., Horberg, E. J., \& Keltner, D. (2010). Compassion, pride, and social intuitions of selfother similarity. Journal of Personality and Social Psychology, 98, 618-630. https://doi.org/10.1037/a0017628

Preston, S. D. (2013). The origins of altruism in offspring care. Psychological Bulletin, 139(6), 1305-1341. https://doi.org/10.1037/a0031755

Preston, S. D., \& De Waal, F. B. (2002). Empathy: Its ultimate and proximate bases. Behavioral and Brain Sciences, 25(1), 1-20. doi: 10.1017/s0140525x02000018 
Prinz, J. (2011). Against empathy. The Southern Journal of Philosophy, 49(s1), 214-233. https://doi.org/10.1111/j.2041-6962.2011.00069.x

Richard, F. D., Bond Jr, C. F., \& Stokes-Zoota, J. J. (2003). One hundred years of social psychology quantitatively described. Review of General Psychology, 7(4), 331-363. DOI: $10.1037 / 1089-2680.7 .4 .331$

Roeser, R. W., Colaianne, B. A., \& Greenberg, M. A. (2018). Compassion and human development: Current approaches and future directions. Research in Human Development, 15(3-4), 238-251. https://doi.org/10.1080/15427609.2018.1495002

Rom, S. C., Katzir, M., Diel, K., \& Hofmann, W. (2019). On trading off labor and leisure: A process model of perceived autonomy and opportunity costs. Motivation Science. Advance online publication. https://doi.org/10.1037/mot0000148

Scheffer, J. A., Cameron, C. D., McKee, S., Hadjiandreou, E., \& Scherer, A. (in press). Stereotypes about compassion across the political spectrum. Emotion. https://doi.org/10.1037/emo0000820

Schumann, K., Zaki, J., \& Dweck, C. S. (2014). Addressing the empathy deficit: Beliefs about the malleability of empathy predict effortful responses when empathy is challenging. Journal of Personality and Social Psychology, 107(3), 475-493. doi: $10.1037 / \mathrm{a} 0036738$

Shaw, L. L., Batson, C. D., \& Todd, R. M. (1994). Empathy avoidance: Forestalling feeling for another in order to escape the motivational consequences. Journal of Personality and Social Psychology, 67(5), 879-887. https://doi.org/10.1037/0022-3514.67.5.879 
Sheppes, G., Scheibe, S., Suri, G., Radu, P., Blechert, J., \& Gross, J. J. (2014). Emotion regulation choice: A conceptual framework and supporting evidence. Journal of Experimental Psychology: General, 143, 163-181. https://doi.org/10.1037/a0030831

Singer, T., \& Klimecki, O. M. (2014). Empathy and compassion. Current Biology, 24(18), R875R878. https://doi.org/10.1016/j.cub.2014.06.054

Stellar, J. E., Cohen, A., Oveis, C., \& Keltner, D. (2015). Affective and physiological responses to the suffering of others: Compassion and vagal activity. Journal of Personality and Social Psychology, 108(4), 572-585. doi: 10.1037/pspi0000010

Stellar, J. E., Manzo, V. M., Kraus, M. W., \& Keltner, D. (2012). Class and compassion: Socioeconomic factors predict responses to suffering. Emotion, 12, 449-459. doi: $10.1037 / \mathrm{a} 0026508$

Stellar, J. E., \& Keltner, D. (2014). Compassion. In M. M. Tugade, M. N. Shiota, \& L. D. Kirby (Eds.), Handbook of positive emotions (p. 329-341). The Guilford Press

Strauss, C., Taylor, B. L., Gu, J., Kuyken, W., Baer, R., Jones, F., \& Cavanagh, K. (2016). What is compassion and how can we measure it? A review of definitions and measures. Clinical Psychology Review, 47, 15-27. doi: 10.1016/j.cpr.2016.05.004

Tamir, M. (2009). What do people want to feel and why? Pleasure and utility in emotion regulation. Current Directions in Psychological Science, 18(2), 101-105. https://doi.org/10.1111/j.1467-8721.2009.01617.x

Toi, M., \& Batson, C. D. (1982). More evidence that empathy is a source of altruistic motivation. Journal of Personality and Social Psychology, 43(2), 281-292. https://doi.org/10.1037/0022-3514.43.2.281 
Valdesolo, P., \& DeSteno, D. (2011). Synchrony and the social tuning of compassion. Emotion, 11(2), 262-266. https://doi.org/10.1037/a0021302

Västfjäll, D., Slovic, P., Mayorga, M., \& Peters, E. (2014). Compassion fade: Affect and charity are greatest for a single child in need. PloS One, 9(6), e100115. https://doi.org/10.1371/journal.pone.0100115

Westbrook, A., Kester, D., \& Braver, T. S. (2013). What is the subjective cost of cognitive effort? Load, trait, and aging effects revealed by economic preference. PLoS One, 8(7), e68210. https://doi.org/10.1371/journal.pone.0068210

Zaki, J. (2014). Empathy: A motivated account. Psychological Bulletin, 140(6), 1608-1647. https://doi.org/10.1037/a0037679

Zaki, J., \& Ochsner, K. N. (2012). The neuroscience of empathy: Progress, pitfalls and promise. Nature Neuroscience, 15(5), 675-680. doi: 10.1038/nn.3085 